Bibliotecas. Vol 37, N 1, enero - junio, 2019. EISSN: 1659-3286

URL: http://www.revistas.una.ac.cr/index.php/bibliotecas/index

DOI: http://dx.doi.org/10.15359/rb.37-1.4

Licencia: Creative Commons (BY-NC-SA) 4.0 Internacional

\title{
Problemática de los mileniales en la competitividad de las empresas tecnológicas durante el 2017
}

\section{Difficulties of Millennials on the Competitiveness of Tech Companies during 2017}

Fernando Gutiérrez Benavides

Fiserv CR

Recibido: 02 de agosto de 2018 Aceptado: 06 de febrero de 2019

Publicado: 19 de junio de 2019

\begin{abstract}
Resumen
La presente indagación busca dar a conocer, mediante una revisión documental de diversas fuentes y un estudio de campo, el nivel de correlación entre las variables: rotación de empleo, desmotivación laboral y carencia de compromiso de los mileniales costarricenses, y el impacto de estas en la competitividad de las empresas tecnológicas de Costa Rica. El indagador realiza una pesquisa en la empresa Fiserv CR, y aplica un cuestionario, para así recabar los datos, y vía un Coeficiente Pearson, determina el grado de afinidad entre dichas aristas, para así probar su hipótesis, y establecer una serie de conclusiones y recomendaciones.
\end{abstract}

Palabras clave: Mileniales, Rotación de Empleo, Desmotivación Laboral, Carencia de Compromiso, Competitividad, Tecnologías, Coeficiente Pearson, Costa Rica.

\begin{abstract}
The following investigation pertains the study of different articles and the application of a field study, in order to determine the positive correlation between the variables: employment rotation, lack of motivation and lack of compromise of the Costa Rican Millennials; as well as, the impact in the competitiveness of the technological companies. The investigator made a study and applied a survey, in the tech company Fiserv CR, in order to obtain relevant information, and with a Pearson Coefficient, he was able to prove the affinity level between the mentioned variables, test his hypothesis and stablish conclusions recommendations.
\end{abstract}

Keywords: Millennials, Employment Rotation, Lack of Motivation, Lack of Compromise, Competitiveness, Technologies, Pearson Coefficient, Costa Rica. 


\section{Introducción}

Durante los últimos siete años, las condiciones laborales en el mercado de capital humano costarricense muestran un cambio vertiginoso, pues existe una feroz competencia por parte de las compañías para atraer y retener al mejor talento disponible. Sin embargo, diversos modelos organizacionales se han visto incapaces de incorporar las necesidades de la Generación Milenial $(\mathrm{Y})$ a las estrategias y objetivos empresariales.

De acuerdo con Nava (2014), los mileniales "son aquellas personas nacidas entre 1980 y el 2000, y son un grupo híper conectado y familiarizado con la tecnología, con importantes repercusiones para la humanidad" (p. 1). De manera complementaria, Benvenuto (2014) añade lo siguiente: "ellos surgen en los albores de la comunicación digital, la telefonía móvil y las redes sociales. Por consiguiente, tienen un manejo diferente de las tecnologías de información" (párr. 8).

Las ideas ejemplificadas con anterioridad permiten entender cuan volátil e incomprendida es dicha generación, principalmente en aspectos relacionados con la rotación de empleo, nivel de motivación y compromiso empresarial. Desde la óptica del indagador, son entes con una visión innovadora en torno al concepto del trabajo, pues lo ven como un medio y no como un fin, lo cual retrasa su incorporación y consolidación en las organizaciones. Al mismo tiempo, buscan dejar su huella en la sociedad, tal y como sus predecesores generacionales.

Por otra parte, desde una óptica tecnológica, Retamal (2007) argumenta que: la administración moderna no siempre tiene pleno control sobre el entorno organizacional lo cual a veces, precipita decisiones urgentes en aspectos fundamentales. De ahí la importancia que las empresas los incorporen en sus cambios tecnológicos, con el fin de garantizar el éxito.

A manera ilustrativa, de acuerdo con el Programa Macroeconómico del Banco Central de Costa Rica del 2016: "las tecnologías de información contribuyeron en casi un $8 \%$ al producto interno bruto nacional, lo cual demuestra el grado de importancia que estas tienen en cuanto a la generación de empleo y fuentes de riqueza" (BCCR, 2017, p. 8). 
Por consiguiente, la presente indagación se centra en determinar cómo las variables: rotación de empleo, desmotivación laboral y carencia de compromiso afectan a los mileniales costarricenses que laboran en las compañías tecnológicas en Costa Rica. Para ello, se realiza una revisión documental y un estudio en la compañía Fiserv CR, la cual se dedica al desarrollo de tecnologías para diversas entidades bancarias en el mundo, y cuya sede principal se encuentra en Barreal de Heredia, con el fin de evaluar el impacto de las aristas mencionadas.

\section{Hipótesis}

El valor teórico de este estudio radica en realizar una revisión exhaustiva de la literatura existente; así como, un análisis mediante la aplicación de un cuestionario, para demostrar si las variables: rotación, desmotivación, y carencia de compromiso laboral han mejorado o desmejorado la competitividad empresarial en las empresas tecnológicas para las cuales trabajan mileniales costarricenses.

Por consiguiente, se parte del método deductivo, el cual de acuerdo con Babbie (2000) permite: describir, recoger, clasificar, resumir y analizar las características de un conjunto de elementos; y esta manera, deducir conclusiones acerca de su estructura o composición. De igual forma, Bisquerra (2000) complementa lo anterior al indicar que: dicha metodología implica el planteamiento de conclusiones por medio de información fehaciente y válida; por lo tanto, utiliza datos e información real, directamente relacionada con el fenómeno de estudio. Por ende, se plantea la siguiente hipótesis de investigación: Existe una correlación positiva entre: la rotación de empleo, la desmotivación laboral y la carencia de compromiso de los mileniales costarricenses, y el nivel de competitividad de las empresas tecnológicas.

\section{Marco Teórico}

Durante los últimos años, diversas empresas cerraron sus operaciones en Costa Rica, lo cual devenga en una cantidad importante de mileniales desempleados. Por lo tanto, es crucial para ellos encontrar nuevas fuentes de empleo para poder aportar sus conocimientos a la sociedad. 
Una de las mejores formas de lograrlo es a través de la incorporación en las empresas de tecnología, las cuales son creadoras de sinergias y motivadoras de retos laborales. "Sin embargo, algunos reclutadores en dichas compañías muestran renuencia a contratarlos, pues desde su perspectiva, dicho grupo generacional es volátil y difícil de controlar" (Álvarez, 2014, párr. 8). Entre las principales razones por las cuales los mileniales constituyen un reto laboral se destacan la: desmotivación, alta rotación, y carencia de compromiso laboral.

Siguiendo la misma línea de acción, Alarcón (2015) plantea lo siguiente acerca de la incapacidad de los mileniales de encajar en la ideología clásica del mercado laboral:

Tienen confianza en sus capacidades, pero les cuesta seguir las órdenes de sus jefes cuando consideran que ellos no tienen las competencias indicadas para guiarlos. Están interesados en la diversidad y aceptan la diferencia, aunque su autosuficiencia disminuya su capacidad para trabajar en equipo. En sus mentes suele dar vueltas la idea de que el trabajo no es su vida, pues están de paso y se encuentran aprendiendo nuevas habilidades, desarrollando su potencial o ahorrando para su próximo objetivo. Por consiguiente, los mileniales procuran sentirse identificados con lo que la empresa hace, vende o produce, con su cultura de trabajo, y con las causas (políticas, sociales o ambientales) en las cuales se encuentra envuelta (párr. 35).

Por consiguiente, la misión de dicho grupo es la de constantemente: "reinventar, innovar y emprender nuevos desafíos" (Álvarez, 2014, párr. 1). Por lo tanto, de acuerdo con este exponente, sus características se pueden resumir de la siguiente manera:

- Son idealistas: se consideran activos y críticos frente a las decisiones gubernamentales.

- Son optimistas: son conscientes de las problemáticas de sus países.

- Son competitivos: buscan mantener su propio estilo de vida.

- Son productores: producen contenidos de interés de acuerdo con sus gustos y áreas de afinidad, y los comparten en sus redes sociales.

En torno a la temática central de la indagación, existen pocas pesquisas relacionadas con la misma. Durante el 2015 y el 2016, las empresas Deloitte Consulting y Softline, realizaron estudios someros acerca de la situación laboral de los mileniales, pero se centraron en datos 
generales, haciendo pocas distinciones en cuanto al tipo de sector y actividad económica. Asimismo, no cuestionaron si este grupo etario impacta o no la competitividad en algún sector empresarial. Por ejemplo, Softline (2016) menciona lo siguiente:

La generación del milenio inunda la fuerza de trabajo, y las empresas deben encontrar la mejor forma de manejarlos. Después de todo, de sus filas surgirá el $75 \%$ de la fuerza laboral en el 2025; y ya hoy en día ocupan el 34\%, de acuerdo con Deloitte Consulting. Es un dilema cultural, pues los trabajadores jóvenes de hoy en día requieren de un tipo de atención que va en contra de lo planteado por las generaciones pasadas (párr. 1).

La afirmación anterior permite entender el impacto del grupo etario del milenio en la fuerza laboral actual, pero adolece de las causas que generan: una elevada rotación, desmotivación y carencia de compromiso de los mileniales en las compañías de tecnología. De manera sintética, las averiguaciones expuestas con anterioridad carecen de explicaciones acerca de cómo: las políticas laborales, el plan de carrera, la flexibilidad, el ambiente laboral, y el salario, afectan la competitividad en las empresas tecnológicas, o bien el por qué: la rotación y la desmotivación, son elementos que pueden mejorar o desmejorar el nivel competitivo en dicho sector.

Uno de los pocos exponentes en esta temática es Hroncich (2017), quien argumenta que este tipo de compañías implementan los mejores ambientes laborales para los mileniales; por lo tanto, la rotación laboral es baja y no influye en la competitividad empresarial, pues el entorno empresarial les brinda mayor contacto con la tecnología y las redes sociales, flexibilidad de horarios, la posibilidad de realizar teletrabajo, lo cual asegura su permanencia por varios años. Sin embargo, exponentes como Gibson y Sodeman (2014) argumentan que: existe poca relación entre las expectativas de los mileniales y los objetivos de las empresas tecnológicas, lo cual obliga a replantear la educación organizacional y el desarrollo de talento. De acuerdo con los autores anteriores, existe cierto grado de relación entre la competitividad y la rotación laboral, pues conforme los mileniales estudian y buscan mejores condiciones profesionales en otros lugares, las compañías de tecnología se ven obligadas a enseñarles a desenvolverse en entornos cambiantes, y a diferenciarse para poder retenerlos. La carencia de información permite al indagador explorar este grado de afinidad mediante fuentes primarias. 
Por otra parte, desde la óptica de Sanz (2015), los mileniales se desmotivan principalmente por: los valores y la cultura organizacional, los canales organizacionales, y la integración de los objetivos de estos con las metas de la empresa. Asimismo, Hewitt y Ukpere (2012) añaden que: los mileniales son entes con necesidades distintas. Por consiguiente, le dan valor a la personalización y a la realimentación continua, aspectos en los cuales las entidades tecnológicas deben invertir continuamente para mantenerlos motivados.

Asimismo, Andert (2011), plantea que: los líderes mileniales buscan enfoques holísticos; por lo tanto, las estructuras mecánicas no tienen sentido, y tampoco las relaciones de líder y seguidor. Es decir, no creen en la ideología de un jefe 24-7 detrás de ellos, ni en realizar una serie de tareas repetitivas, lo cual ocasiona una severa desmotivación y frustración en dicho grupo.

Finalmente, en cuanto a la carencia de compromiso de los mileniales en las empresas tecnológicas, Meister y Willyerd (2010) argumentan que obedece a cuatro variables: reclutamiento, interconectividad, flexibilidad laboral, promociones. Por consiguiente, los mileniales abandonan estas compañías cuando: a) la cultura organizacional los limita, b) existe poca apertura en el pensamiento, y c) los valores empresariales no integran al milenial con la persecución de metas a lo largo y ancho de la empresa.

\section{Metodología}

Dado el planteamiento hipotético de la indagación, se estableció una relación entre las variables: rotación de empleo, desmotivación y carencia de compromiso; y cómo estas, afectan a los mileniales costarricenses y a la competitividad laboral en las empresas tecnológicas.

Por otra parte, se utilizó un enfoque mixto, pues mediante la revisión documental se buscó entender la extensión y los alcances de otras indagaciones en torno a dicha temática; y al mismo tiempo, permitió complementar y contrastar los resultados develados por la presente investigación. De esta forma, se evaluó la parte cualitativa. Al mismo tiempo, los datos del cuestionario se codificaron en tablas para generar figuras, y vía el Coeficiente de Pearson, se realizaron una serie de correlaciones, lo cual a su vez ayudó al indagador a realizar 
Bibliotecas. Vol. 37, № 1, enero - junio, 2019. EISSN: 1659-3286

URL: http://www.revistas.una.ac.cr/index.php/bibliotecas/index

conclusiones y recomendaciones con base en la información develada. De esta manera, se evaluó el aspecto cuantitativo. Seguidamente, se describen los métodos utilizados:

\section{a) Método utilizado para la revisión documental}

Para el presente estudio, se partió de fuentes electrónicas de la base de datos de Google Académico, pues desde una óptica personal este constituye un motor de búsqueda con una gran variedad de artículos y de referencias; y al mismo tiempo, brindó acceso a filtros por rangos de fechas determinados.

Por otra parte, se utilizaron como palabras claves las siguientes: rotación de empleo, compromiso laboral, desmotivación, mileniales, competitividad empresarial, empresas de tecnología. A través de la revisión sistemática de la información existente, se enlazaron las aristas mencionadas con el objetivo de validar la hipótesis. Asimismo, se agruparon las fuentes literarias en un rango de tiempo específico (2010 al 2017), pues coincidieron con dos aspectos fundamentales de la indagación: el auge de las empresas tecnológicas en la presente década, y la incorporación de los mileniales a la fuerza laboral en este tipo de compañías.

La exploración inicial develó una cantidad limitada de literatura relacionada con la temática propuesta. Por ende, se partió de búsquedas individuales de palabras en un rango de tiempo específico (2010-2017), y se seleccionaron aquellos con más de diez citaciones de otros autores. Lo anterior, generó una base de más de cincuenta fuentes electrónicas, las cuales se revisaron de acuerdo con dos criterios: 1) los resúmenes de cada artículo, y 2) su relación con la temática de la investigación. De acuerdo con estos criterios, se redujo la cantidad de reseñas a treinta, las cuales se agruparon de la siguiente manera como se muestra en el Cuadro 1: 
Bibliotecas. Vol. 37, № 1, enero - junio, 2019. EISSN: 1659-3286

URL: http://www.revistas.una.ac.cr/index.php/bibliotecas/index

Cuadro 1

Agrupamiento de referencias

\begin{tabular}{|l|c|c|}
\hline \multicolumn{1}{|c|}{ Variable de investigación } & $\begin{array}{c}\text { Cantidad de artículos } \\
\text { relacionados }\end{array}$ & $\begin{array}{c}\text { Rango de tiempo } \\
\text { (en años) }\end{array}$ \\
\hline $\begin{array}{l}\text { Rotación de la fuerza laboral milenial en las } \\
\text { empresas de tecnologías de información y } \\
\text { comunicación. }\end{array}$ & 5 & 2014 \\
\hline $\begin{array}{l}\text { Desmotivación de la fuerza laboral milenial en } \\
\text { las empresas de tecnologías de información y } \\
\text { comunicación. }\end{array}$ & 20 & 2016 \\
\hline $\begin{array}{l}\text { Carencia de compromiso milenial en las } \\
\text { empresas de tecnologías de información y } \\
\text { comunicación. }\end{array}$ & & 2010 \\
\hline
\end{tabular}

Fuente: Elaboración Propia (2017)

\section{b) Método utilizado para la investigación de campo}

A través de una correlación de variables vía el Coeficiente de Pearson, se estudia cómo la rotación de empleo, la desmotivación y la carencia de compromiso afectan a los mileniales costarricenses y a la competitividad empresarial en las empresas para las cuales trabajan. Para esta indagación, se seleccionó a la compañía Fiserv CR, quien es la líder mundial en el desarrollo de software bancario, y cuenta con más de 20.000 empleados en todo el mundo. En Costa Rica, genera más de 600 empleos directo, y si bien las empresas tecnológicas se constituyen diversos segmentos, los resultados de la presente sirven como un punto de comparación para futuras pesquisas; ya sea en este campo, o en ámbitos similares.

Asimismo, se utilizó un diseño transversal (también conocido como transeccional), el cual de acuerdo con el sitio web de Organización de Técnicas de Estudio (2017): fomenta la recolección de datos en un solo espacio del tiempo. Su propósito se centra en describir las incógnitas y examinar su incidencia e interrelación en un momento dado. Además, se escogió el tipo correlacional/causal pues describe las relaciones entre dos o más variables. Es decir, explora el siguiente tipo de relación (Figura 1): 
Bibliotecas. Vol. 37, № 1, enero - junio, 2019. EISSN: 1659-3286

URL: http://www.revistas.una.ac.cr/index.php/bibliotecas/index

Figura 1

Relación de variables

Aristas de la indagación

Rotación de Empleo

Desmotivación

Carencia de

Compromiso
Población de estudio

Mileniales que

laboran en empresa

de tecnología

Fiserv CR.

\section{Pregunta e Hipótesis}

\section{Pregunta:}

¿Mejoran o no la competitividad empresarial en la empresa Fiserv CR?

Hipótesis:

Existe una correlación positiva entre las variables y la competitividad.

Fuente: Elaboración Propia (2017).

\section{c) Instrumento para la recolección de datos}

Para recabar los resultados de campo, se aplicó el cuestionario denominado: Perspectivas de los mileniales costarricenses sobre el impacto de las variables: rotación de empleo, desmotivación y carencia de compromiso laboral en las compañías tecnológicas que radican en Costa Rica. El mismo constaba de siete preguntas cerradas, de las cuales cuatro son de escala de opinión (tipo Likert) y tres son de selección múltiple. Por otra parte, el Cuadro 2 explica de una mejor forma la información que se recolectó vía el cuestionario.

\section{Cuadro 2}

\section{Información recabada vía el cuestionario}

\begin{tabular}{|c|l|}
\hline $\begin{array}{c}\text { Población de } \\
\text { interés }\end{array}$ & $\begin{array}{l}\text { Mileniales (personas cuya fecha de nacimiento se encuentra entre 1980- } \\
\text { 2000) costarricenses mayores de edad, y que laboren en la empresa } \\
\text { tecnológica Fiserv CR, al menos desde el 2016. }\end{array}$ \\
\hline \multirow{3}{*}{ Muestra } & $\begin{array}{l}65 \text { mileniales costarricenses que laboren en la empresa Fiserv CR, en las } \\
\text { sedes de Barreal de Heredia y Tres Ríos Cartago, al menos desde el 2016. } \\
\text { Se seleccionó dicha empresa por comodidad, pues el indagador labora allí, } \\
\text { y pudo recabar los datos en un horario de lunes a viernes (de 8am a 5pm) } \\
\text { con mayor facilidad. }\end{array}$ \\
\hline
\end{tabular}




\begin{tabular}{|c|l|}
\hline $\begin{array}{c}\text { Tipo de } \\
\text { muestreo: No } \\
\text { probabilístico }\end{array}$ & $\begin{array}{l}\text { Para poder dar solución a la hipótesis, se selecciona el muestreo por } \\
\text { conveniencia, el cual se entiende como: "un subgrupo de la población } \\
\text { donde la elección de los elementos no depende de la probabilidad sino de } \\
\text { las características de la investigación" (Hernández et al., 2010, p. 176). } \\
\text { Para la presente pesquisa, el indagador parte de una población y contextos } \\
\text { específicos. }\end{array}$ \\
\hline $\begin{array}{c}\text { Unidad } \\
\text { informante }\end{array}$ & $\begin{array}{l}\text { Mileniales costarricenses de entre 18-37 años que laboran en las sedes de } \\
\text { Barreal de Heredia y Tres Ríos Cartago de la empresa Fiserv CR, al menos } \\
\text { desde el 2016. }\end{array}$ \\
\hline
\end{tabular}

Fuente de elaboración: Propia (2017).

\section{d) Muestra}

El cuestionario se aplicó en la compañía Fiserv CR, la cual cuenta con una población total de seiscientas personas, de las cuales aproximadamente el 60\% (360 personas) son mileniales. Dicha compañía se dedica al desarrollo de tecnologías para el sector bancario. Para calcular la muestra, se utilizó la siguiente fórmula para una población finita:

\section{$N \times Z^{\wedge} 2 \times p \times q$ \\ $\overline{D^{\wedge} 2 \times(N-1)+Z^{\wedge} 2 \times p \times q}$}

Donde:

$Z=$ Es la constante que depende del nivel de confianza asignado

$\mathrm{P}=$ Probabilidad de éxito

$Q=$ Probabilidad de fracaso $(1-P)$

$\mathrm{N}=$ Tamaño de la población

$\mathrm{D}=$ Error máximo admitido

Por consiguiente, para un nivel de confianza del $95 \%$, con una probabilidad de éxito del $5 \%$, y un error máximo del $5 \%$, se obtiene una muestra de:

$600 \times\left(1,96^{\wedge} 2\right) \times 0.05 \times 0.95$ $=65$ personas

$\left(0.05^{\wedge} 2\right) \times(600-1)+1.96^{\wedge} 2 \times 0.05 \times 0.95$ 
La muestra se obtuvo del total de empleados de Fiserv CR, una vez obtenido el número de personas que se tenían que entrevistar, este número se aplicó a conveniencia entre la población de mileniales de las sedes de Barreal de Heredia y Tres Ríos Cartago, cuyas edades se encontraban entre los 18 y 37 años, y que tenían al menos un año de trabajar en la empresa, y se aplicó en la semana del 19 al 23 de junio del 2017, en horas laborales de 8 am a 5 pm.

\section{e) Coeficiente de Correlación de Pearson}

Para la presente pesquisa, se realizó un análisis correlacional mediante el Coeficiente de Pearson, esto con el fin de medir el nivel de afinidad entre la competitividad empresarial y las aristas indicadas, utilizando los siguientes supuestos (Cuadro 3):

\section{Cuadro 3}

\section{Supuestos para el Coeficiente de Correlación de Pearson}

\begin{tabular}{|c|c|c|c|c|}
\hline $\begin{array}{c}\text { Variable } \\
\text { Independiente }\end{array}$ & $\begin{array}{c}\text { Variable } \\
\text { Dependiente }\end{array}$ & $\begin{array}{c}\text { Relación de datos } \\
\text { utilizados }\end{array}$ & $\begin{array}{c}\text { Nivel de } \\
\text { correlación }\end{array}$ & $\begin{array}{c}\text { Tamaño de la } \\
\text { muestra }\end{array}$ \\
\hline $\begin{array}{l}\text { Rotación de } \\
\text { Empleo }\end{array}$ & Desmotivación & $\begin{array}{l}\text { Posibilidades de } \\
\text { crecimiento vs. } \\
\text { Oportunidades de } \\
\text { Crecimiento }\end{array}$ & \multirow{3}{*}{$\begin{array}{c}r=1: \text { Correlación } \\
\text { Positiva } \\
\text { Perfecta. } \\
0<r<1: \\
\text { Correlación } \\
\text { Positiva. } \\
r=0: \text { No existe } \\
\text { correlación } \\
-1<r<0 \\
\text { Correlación } \\
\text { negativa. } \\
r=-1 \text { Correlación } \\
\text { negativa } \\
\text { perfecta. }\end{array}$} & \multirow{3}{*}{$\begin{array}{c}65 \text { mileniales } \\
\text { costarricenses } \\
\text { que laboran en } \\
\text { la empresa } \\
\text { Fiserv CR, en } \\
\text { las sedes de } \\
\text { Barreal de } \\
\text { Heredia y Tres } \\
\text { Ríos Cartago, a } \\
\text { menos desde el } \\
2016 .\end{array}$} \\
\hline Desmotivación & $\begin{array}{l}\text { Carencia de } \\
\text { Compromiso }\end{array}$ & $\begin{array}{l}\text { Oportunidades de } \\
\text { crecimiento vs } \\
\text { Participación en la } \\
\text { toma de } \\
\text { decisiones }\end{array}$ & & \\
\hline $\begin{array}{c}\text { Carencia de } \\
\text { Compromiso } \\
\text { (independiente) } \\
\text { y (dependiente) }\end{array}$ & $\begin{array}{l}\text { Rotación de } \\
\text { Empleo }\end{array}$ & $\begin{array}{c}\text { Participación en la } \\
\text { toma de } \\
\text { decisiones } \\
\text { vs } \\
\text { Posibilidades de } \\
\text { Crecimiento }\end{array}$ & & \\
\hline
\end{tabular}

Fuente: Elaboración Propia (2017). 


\section{Resultados de campo y su análisis}

\section{a) Rotación de empleo}

Como bien se aprecia en la siguiente Figura 2, el aspecto que genera la mayor rotación de empleados en la compañía de tecnología Fiserv $\mathrm{CR}$, es la ausencia de posibilidades de crecimiento. De acuerdo con la percepción de los 65 mileniales encuestados, en los últimos tres años no han logrado posicionarse en puestos gerenciales o en mandos intermedios, a pesar de contar con un nivel de educación de licenciatura o superior, y de conocer ampliamente el producto en el cual trabajan.

\section{Figura 2}

\section{Principales aspectos que detonan la rotación laboral de los mileniales que trabajan en} Fiserv CR

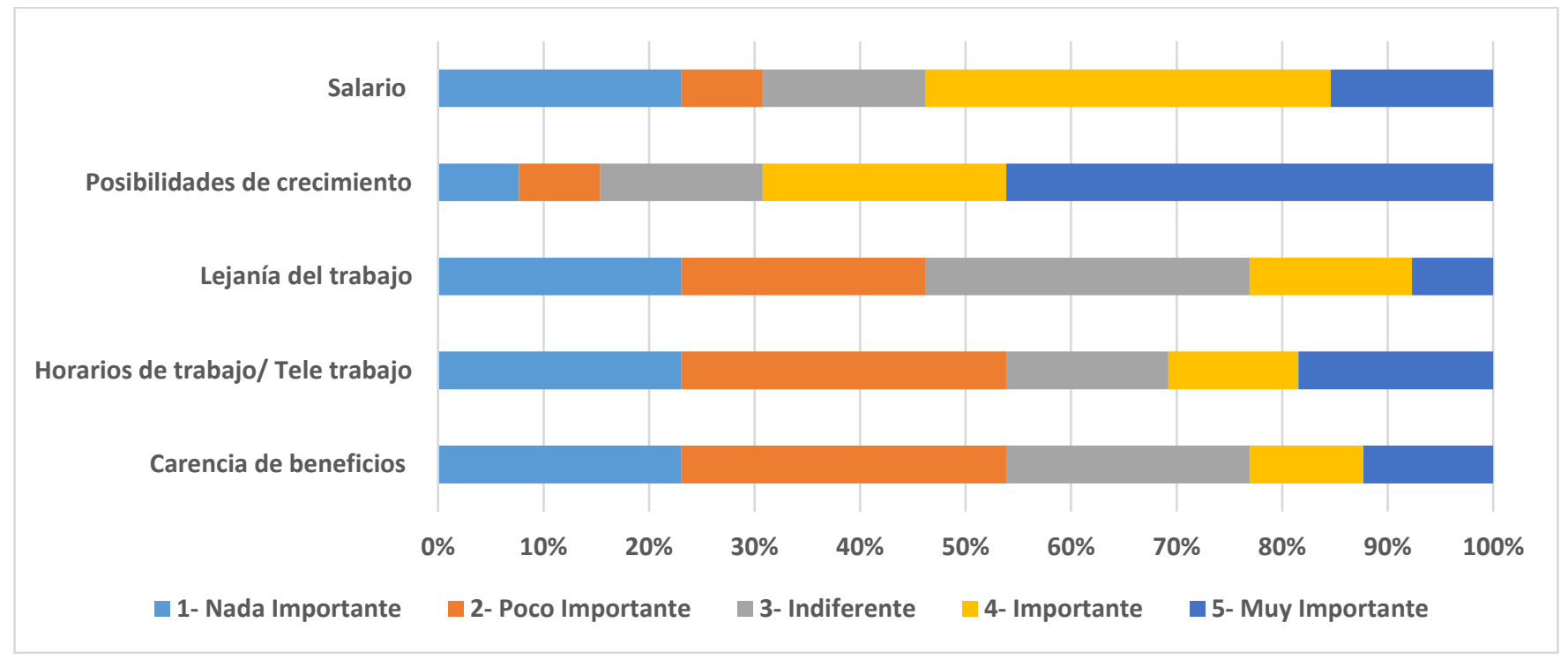

Fuente: Elaboración Propia (2017).

De acuerdo con los resultados de la encuesta, el $46 \%$ de los entrevistados considera como muy importante las oportunidades de crecimiento, mientras el $18 \%$ le da atención especial a la flexibilidad horaria y a poder realizar tele trabajo; y fue la segunda razón por la cual renunciaron a puestos en otras compañías para laborar en Fiserv CR. Además, el 38\% de los encuestados valora como "importante" el aspecto salarial; y desde su perspectiva, en el sector tecnológico 
Bibliotecas. Vol. 37, № 1, enero - junio, 2019. EISSN: 1659-3286

URL: http://www.revistas.una.ac.cr/index.php/bibliotecas/index

existen grandes brechas salariales entre un puesto y otro, o bien dentro de las mismas unidades de negocios, lo cual genera sensaciones de inequidad.

Lo anterior se complementa con un estudio de Alarcón (2015), el cual destaca: como uno de cada tres mileniales le da prioridad a la hora de vincularse a una organización, a la libertad de acceso a las redes sociales, tele trabajo, y a la flexibilidad horaria por encima del salario. Sin embargo, el $28 \%$ de los entrevistados en el estudio de Alarcón valora tener un sueldo alto y un trabajo significativo, por lo cual el $43 \%$ de ellos abandona su empleo cuando percibe inequidades salariales, y que este se encuentra por debajo de sus expectativas.

Por consiguiente, si el salario y las posibilidades de crecimiento no son las idóneas, este grupo etario se retira de las organizaciones, generando rotación y una pérdida de competitividad. Esto obliga a las compañías tecnológicas a revisar continuamente sus paquetes de beneficios y el diseño de puestos, lo cual tiende a elevar el nivel competitivo del sector al ofrecer mejores condiciones laborales con el fin de capturar o retener al talento milenial.

\section{b) Desmotivación laboral}

Los datos de la Figura 3 muestran un paralelismo con lo expuesto por Softline (2016) en el apartado del estado del arte, y cómo las compañías del sector tecnológico son incapaces de poder atender las necesidades laborales de los mileniales en áreas cruciales como: políticas laborales, plan de carrera, lealtad, autonomía, flexibilidad, ambiente laboral y salario.

En torno a las oportunidades de crecimiento y a un plan de carrera profesional, el $54 \%$ de los encuestados destacan la ausencia de posibilidades de crecimiento a futuro dentro de la compañía Fiserv CR. Por consiguiente, se sienten desmotivados y buscan nuevas oportunidades en alguna otra organización tecnológica. De manera paralela, un estudio elaborado por Fernández (2012) destaca que: "el 54\% de los mileniales tienen un título universitario; sin embargo, al llegar al mercado laboral se encuentran con puestos rígidos, por lo cual el $50 \%$ de ellos prefiere no tener un empleo a estar en uno que odien" (párr. 11). 
Bibliotecas. Vol. 37, № 1, enero - junio, 2019. EISSN: 1659-3286

URL: http://www.revistas.una.ac.cr/index.php/bibliotecas/index

Figura 3

Principales factores que detonan la desmotivación laboral de los mileniales que trabajan en Fiserv CR

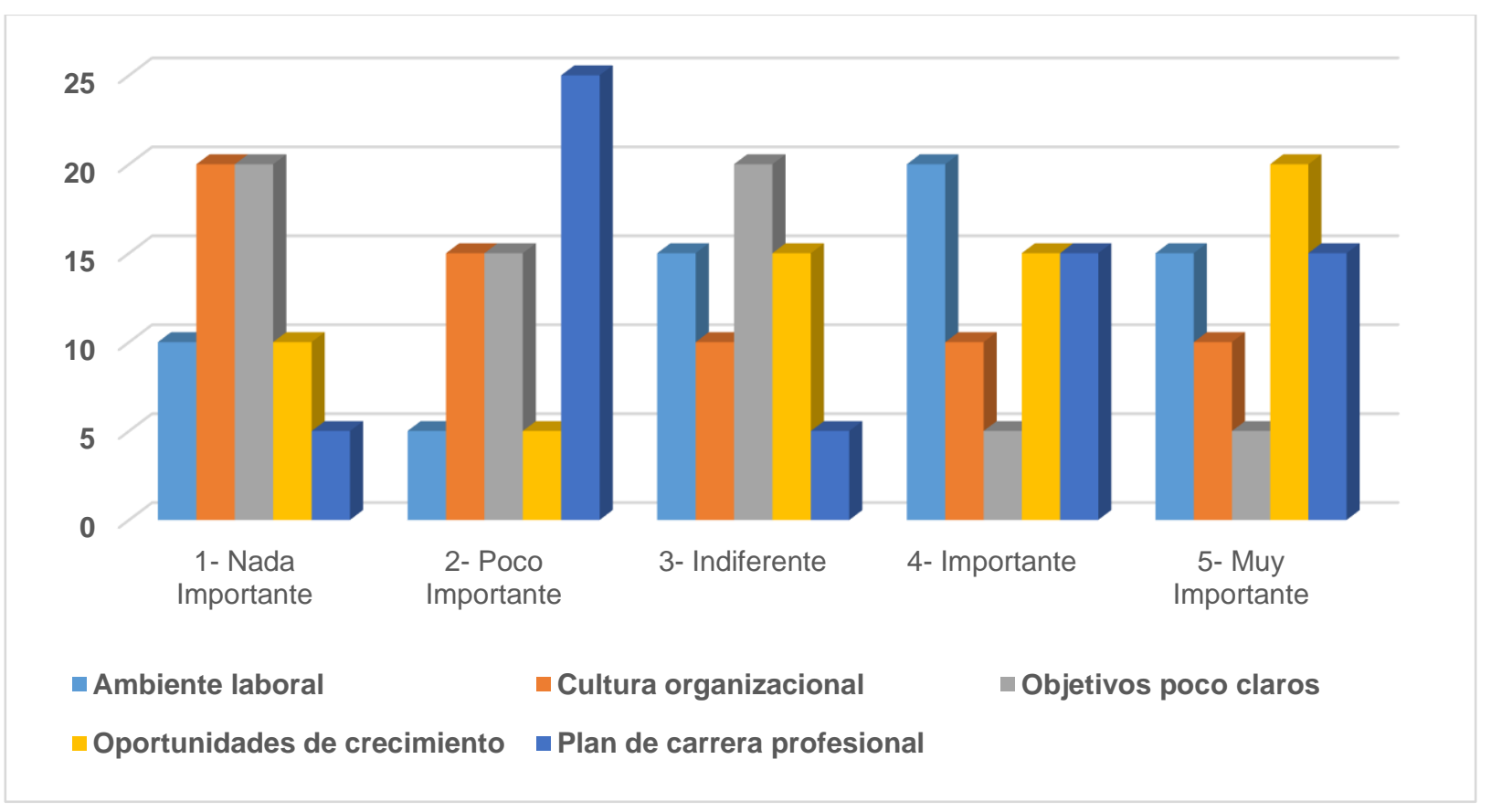

Fuente: Elaboración Propia (2017).

La apreciación de Fernández se manifiesta también en la compañía Fiserv CR, en la cual el $60 \%$ de los encuestados tienen un grado académico superior al bachillerato universitario, e incluso cuentan con certificaciones en el campo tecnológico, pero las gerencias medias y superiores los mantienen relegados a puestos con poca participación e injerencia en la toma de decisiones; por consiguiente, las oportunidades de crecimiento se vuelven escasas.

Por otra parte, Ortega (2015) resalta como: "los primeros trabajos de los mileniales no suelen cumplir con sus expectativas, pues carecen de: conectividad, colaboración, sociabilidad, entre otros, a pesar de encontrarse en entornos tecnológicos" (párr. 17). De manera paralela con la teoría, la indagación devela la poca importancia dada por los encuestados mileniales a la cultura organizacional y a la claridad en la redacción de objetivos en las compañías tecnológicas. 
Bibliotecas. Vol. 37, № 1, enero - junio, 2019. EISSN: 1659-3286

URL: http://www.revistas.una.ac.cr/index.php/bibliotecas/index

Al indagar más sobre este punto, el $62 \%$ de los entrevistados opinan que tienen poca injerencia en la toma de decisiones estratégicas y en la cultura organizacional. Por lo tanto, a pesar de los esfuerzos gerenciales por querer conocer las opiniones de sus asociados vía encuestas, los mileniales se niegan a completarlas o las borran de sus correos, pues no perciben mejorías en las condiciones laborales.

Por consiguiente, si una empresa tecnológica no diseña adecuadamente planes de transición de roles, o genera oportunidades de crecimiento para sus empleados, el grupo etario milenial decide abandonar dicha organización, lo cual le resta competitividad a la misma, al perder no solo talento; sino también, la innovación del cambio generacional. Por ende, existe una relación estrecha entre las oportunidades de crecimiento, un plan para alcanzar un óptimo desarrollo profesional, y el nivel de motivación de los mileniales en las organizaciones tecnológicas. Esta develación reafirma lo expuesto previamente por parte de Alarcón (2015) en el estado del arte.

\section{c) Carencia de compromiso}

La Figura 4 resalta como: el liderazgo, el plan de carrera y la participación en la toma de decisiones son los puntos en los cuales la empresa de tecnología Fiserv CR debe mejorar para aumentar el compromiso de los asociados, en especial de la Generación Y. De acuerdo con la opinión del $77 \%$ de los mileniales encuestados, muchas organizaciones tecnológicas en Costa Rica adolecen de tres problemas comunes: 1) ausencia de preparación previa a la hora de ascender a una persona a un puesto gerencial o de mando medio, 2) poca inclusión de los empleados en la formulación de objetivos y en la toma de decisiones, y 3) escasa participación de los gerentes o líderes de equipo para capacitar a sus asociados. 
Bibliotecas. Vol. 37, № 1, enero - junio, 2019. EISSN: 1659-3286

URL: $\underline{\text { http://www.revistas.una.ac.cr/index.php/bibliotecas/index }}$

Figura 4

Principales factores que detonan la carencia de compromiso laboral de los mileniales que trabajan en Fiserv CR

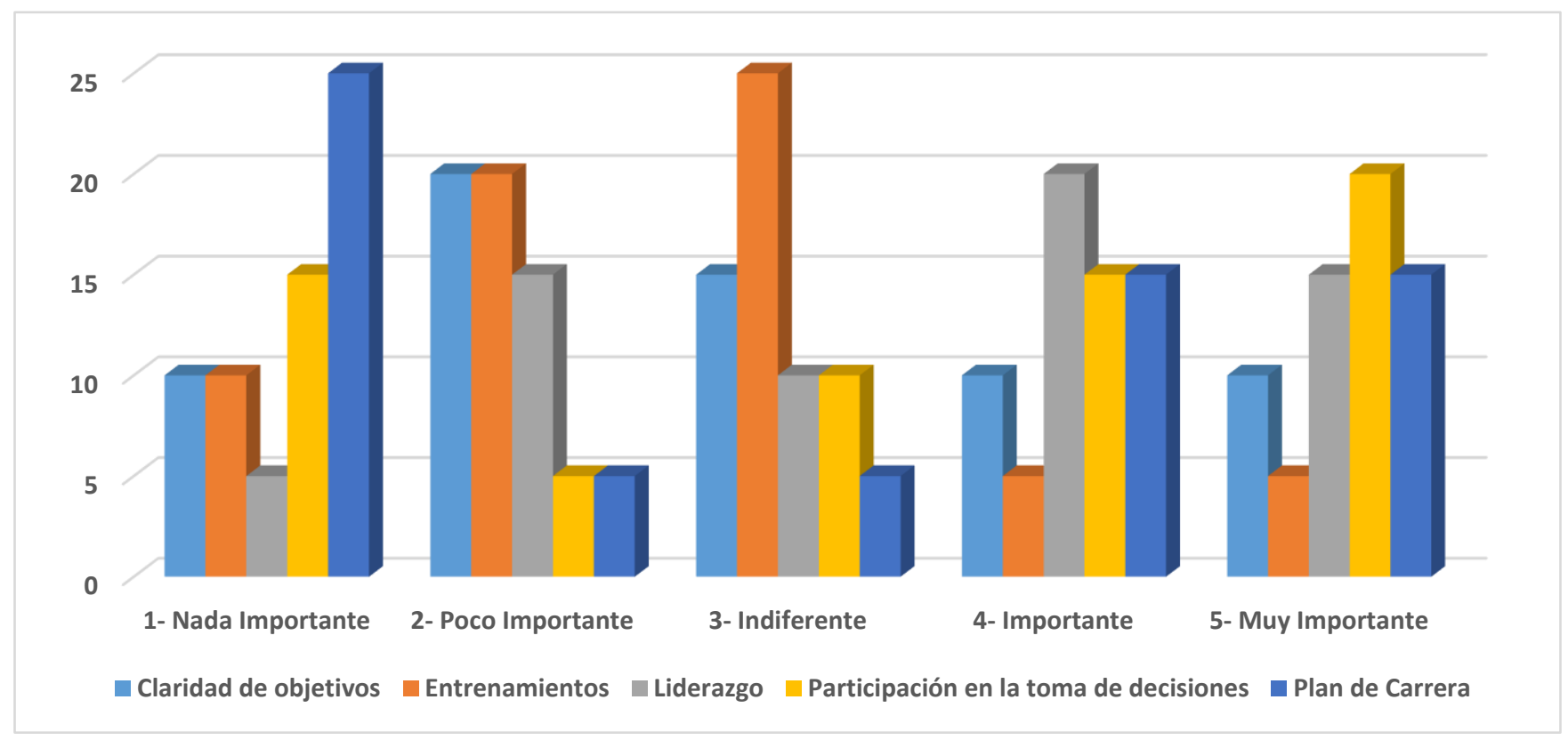

Fuente: Elaboración Propia (2017).

De acuerdo con la posición del $31 \%$ de los entrevistados, ellos están en la compañía por su salario mensual, y no desean inmiscuirse en actividades de desarrollo profesional, pues no se identifican con la cultura organizacional ni con la imagen empresarial. Esto va de la mano con el planteamiento de Ortega (2015) pues: "muchas veces, los mileniales deciden abandonar sus trabajos porque piensan que no reciben la realimentación de sus superiores al momento de proponer ideas" (párr. 12).

Por consiguiente, las respuestas develadas permiten entender el por qué en la Figura 5, el 73\% de los mileniales encuestados cree que la desmotivación laboral, la carencia de compromiso y la rotación de empleo impactan la competitividad de una empresa tecnológica. De acuerdo con su percepción, al no existir retos ni oportunidades de crecimiento, ni un estilo de liderazgo capaz de guiarlos en la consecución de objetivos personales, se desmotivan, pierden el compromiso y deciden irse de la compañía. 


\section{Figura 5}

¿Considera usted que la rotación de empleo, la desmotivación laboral y la carencia de compromiso laboral impactan la competitividad laboral de las empresas tecnológicas en Costa Rica?

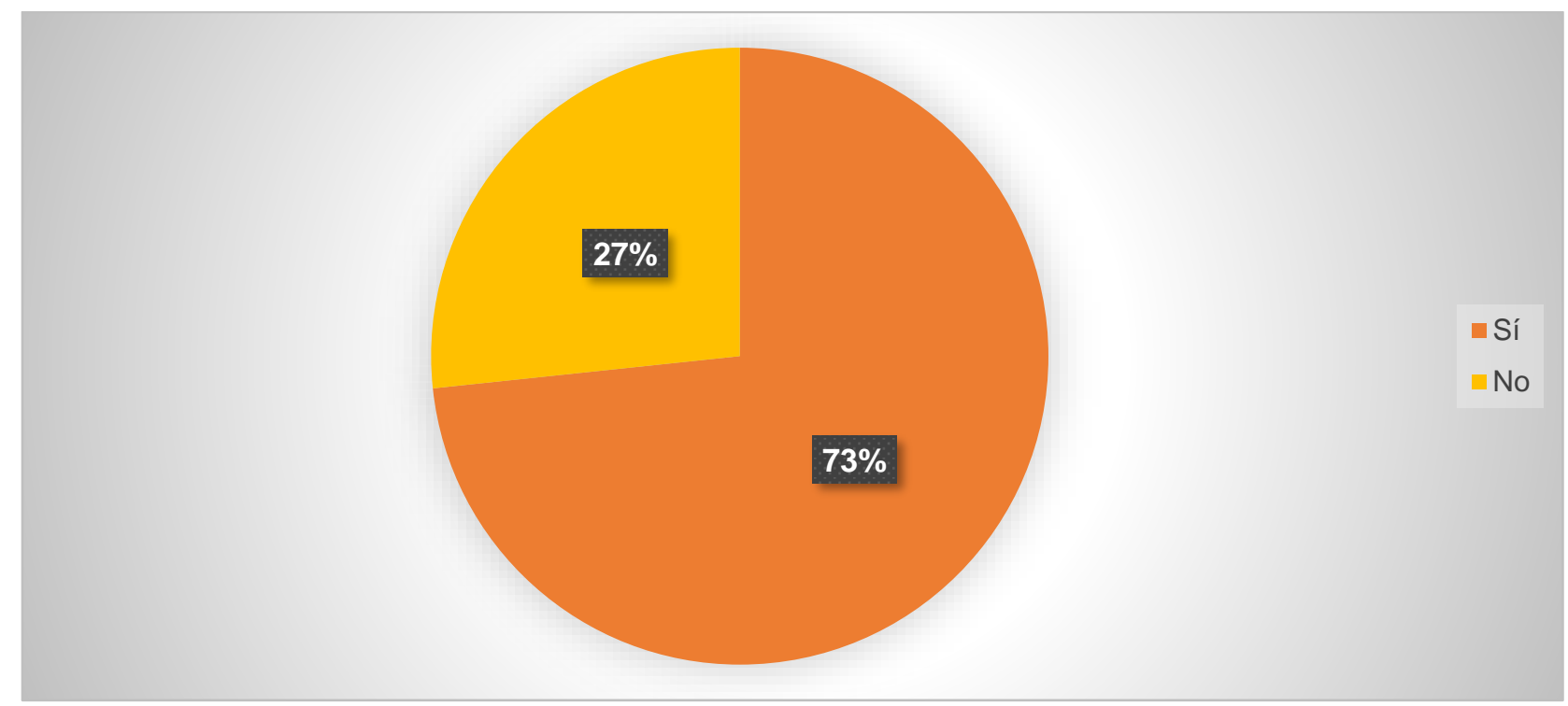

Fuente: Elaboración Propia (2017).

Sin embargo, de acuerdo con la opinión del $73 \%$ de los mileniales entrevistados, las variables descritas con anterioridad también pueden ayudar a las organizaciones tecnológicas a invertir más en el desarrollo profesional de sus empleados, y a permitirles trascender dentro de la organización, lo cual a su vez devenga en oportunidades de participación en la toma de decisiones empresariales; y a mediano plazo, fomenta un cambio en la cultura organizacional. Lo anterior es complementado por Emeagwali (2011), quien propone 7 atributos que las empresas tecnológicas deben aplicar para lograr adhesión de los mileniales en la organización:

- Sentimiento de pertenencia: si los mileniales no llegan a identificarse con la causa de la entidad, deciden retirarse hacia otra empresa.

- Protección: el milenial busca que su lugar de trabajo sea una extensión de su hogar.

- Optimismo: a diferencia de sus antecesores, los mileniales tratan de ver un futuro mejor a pesar de las circunstancias actuales.

- Orientación al equipo: crear lazos entre compañeros y líderes. 
- Versátiles: los mileniales buscan redefinir las reglas y los procesos, por lo cual reprueban entornos en los cuales se les limite o no valoren sus aportes.

- Presión: los mileniales buscan ser sus mejores versiones y cumplir sus ambiciones, por ende fustigan a las empresas que no les permiten alcanzar sus objetivos.

- Logros: si no hay algo que lograr se desmotivan.

De manera sintética, dichas aristas fomentan a las organizaciones tecnológicas a invertir continuamente en el desarrollo del talento humano, pues de lo contrario el gasto por capacitar nuevamente a un empleado, el motivarlo con un paquete de incentivos para que se adhiera a la organización, y el crear un vínculo entre él y la empresa, es sumamente elevado.

d) Correlación de las variables: Rotación de empleo, Desmotivación laboral y Carencia de compromiso

Como bien se denota en la Figura 6, el 54\% por ciento de los mileniales encuestados considera que la desmotivación laboral es el principal elemento que impacta la competitividad empresarial en la organización tecnológica Fiserv CR durante el 2017.

Figura 6

Aspectos que impactan en la competitividad de la empresa tecnológica Fiserv CR durante el 2017

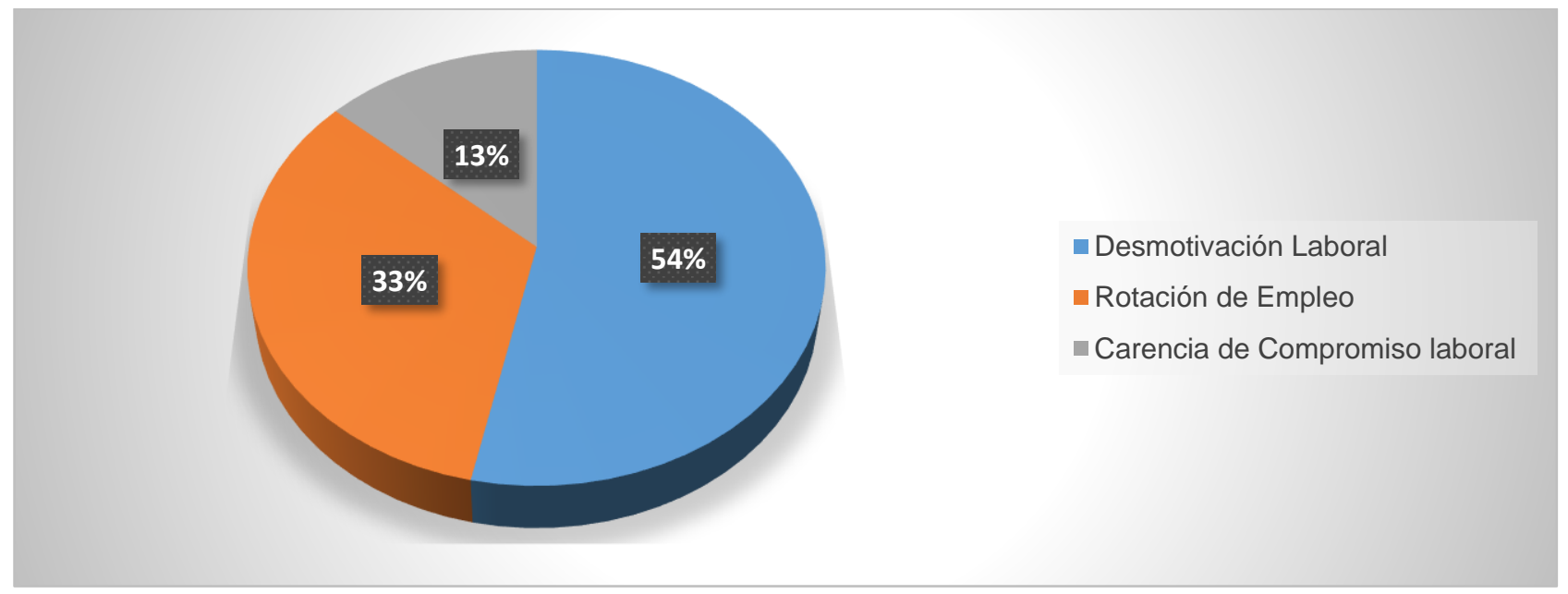

Fuente: Elaboración Propia (2017). 
Desde la óptica de los entrevistados, cuando un asociado no se identifica con la empresa o no se le permite participar de manera activa, se desmotiva al punto de no comprometerse con los objetivos y las metas y, finalmente, decide partir a una organización en la cual le serán reconocidas sus cualidades. Además, el 33\% menciona que muchos mileniales no esperan si quiera a desmotivarse en su totalidad, y se van antes de estar en un lugar poco retador.

Finalmente, la Figura 7 devela una serie de aspectos relevantes acerca de cómo podrían ser más competitivas las compañías tecnológicas en Costa Rica. Las medidas se enfocan principalmente en: 1) redefinir el estilo de liderazgo, 2) mejorar las condiciones laborales actuales, y 3) brindar mayor participación a los empleados en la toma de decisiones.

\section{FIGURA 7}

\section{Principales factores que detonan la carencia de compromiso laboral de los mileniales que trabajan en Fiserv CR}

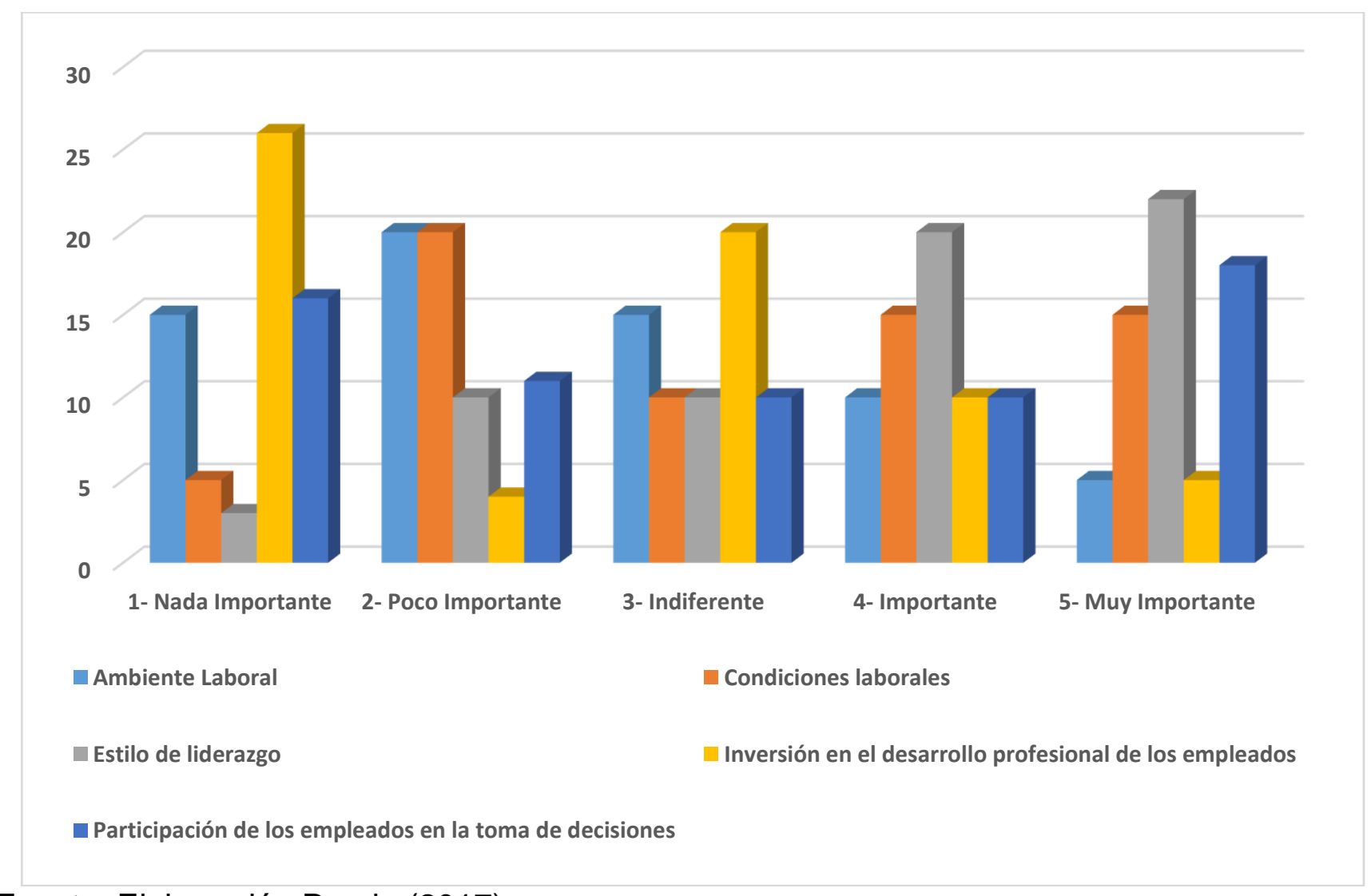

Fuente: Elaboración Propia (2017). 
En cuanto a los tres puntos indicados previamente, los mileniales entrevistados opinan que los líderes del sector tecnológico costarricense deben enfocarse en ayudarlos a: desarrollar su potencial a plenitud, a cumplir sus objetivos, y a involucrarlos en la toma de decisiones. Es decir, un liderazgo orgánico y flexible, y no uno autocrático. Morgan (1986) plantea la necesidad de que: los gerentes, desarrollen la habilidad de realizar lecturas de las diversas situaciones organizacionales, y sean capaces de liderar con estrategia.

De esta manera, "se sienten más comprometidos con los objetivos empresariales, cuando se les toma en cuenta y se sienten incorporados en los aspectos relevantes a la toma de decisiones en una organización" (Méndez, 2014a, p. 12). Además, "un líder participativo, en lugar de tomar decisiones autocráticas, busca envolver al personal en el proceso" (Méndez, 2014b, p. 13).

Ergo, los mileniales que laboran en el sector tecnológico adoptan una actitud colaborativa cuando ellos están trabajando sobre metas conjuntas, pues el compromiso social es mayor y por lo tanto, incrementa la responsabilidad en la toma de decisiones. Asimismo, la indagación devela como el $40 \%$ de los encuestados le dan poco valor a si la empresa Fiserv CR invierte en ellos para su desarrollo profesional a través de capacitaciones o entrenamientos, pues comprenden que la posición financiera de la empresa varía entre unidades de negocios, y algunas de ellas no cuentan en la actualidad con los recursos para poder invertir en un mayor desarrollo profesional de sus asociados.

Por lo anterior, los entrevistados consideran que existen inequidades en dicha compañía a la hora de invertir en actividades de formación. La idea propuesta por Davis y Newstrom (2003), en la cual: "los empleados tienden a juzgar la justicia mediante la comparación de los resultados de sus esfuerzos contra los realizados por otras personas" (p. 144), se vive a menudo por parte del $40 \%$ de los mileniales encuestados, pues consideran que de acuerdo con el líder y a la unidad de negocio para la cual laboren, existen mejores condiciones laborales, oportunidades de integración y de participación en la toma de decisiones. Por lo tanto, para concluir este apartado, se presentan las correlaciones de variables en el Cuadro 4, y sus cálculos se presentan en los anexos. 
Bibliotecas. Vol. 37, № 1, enero - junio, 2019. EISSN: 1659-3286

URL: http://www.revistas.una.ac.cr/index.php/bibliotecas/index

\section{Cuadro 4}

Resultados de las correlaciones de variables

\begin{tabular}{|c|c|c|c|c|c|}
\hline $\begin{array}{c}\text { Variable } \\
\text { Independiente }\end{array}$ & $\begin{array}{c}\text { Variable } \\
\text { Dependiente }\end{array}$ & $\begin{array}{c}\text { Relación de } \\
\text { datos } \\
\text { utilizados } \\
\text { Posibilidades }\end{array}$ & $\begin{array}{c}\text { Coeficiente } \\
\text { Pearson }\end{array}$ & $\begin{array}{c}\text { Tipo de } \\
\text { Correlación }\end{array}$ & $\begin{array}{c}\text { Grado de } \\
\text { Influencia }\end{array}$ \\
\hline $\begin{array}{c}\text { Rotación de } \\
\text { Empleo }\end{array}$ & Desmotivación & $\begin{array}{c}\text { vs } \\
\text { Oportunidades } \\
\text { de Crecimiento }\end{array}$ & 0.934 & $\begin{array}{c}\text { Positiva } \\
0<C P<1\end{array}$ & 0.872 \\
\hline Desmotivación & $\begin{array}{c}\text { Carencia de } \\
\text { Compromiso }\end{array}$ & $\begin{array}{c}\text { Oportunidades } \\
\text { vs } \\
\text { Participación en } \\
\text { la toma de } \\
\text { decisiones }\end{array}$ & 0.975 & $\begin{array}{c}\text { Positiva } \\
0<C P<1\end{array}$ & 0.951 \\
\hline $\begin{array}{c}\text { Carencia de } \\
\text { Compromiso } \\
\text { (independiente) } \\
\text { y (dependiente) }\end{array}$ & $\begin{array}{c}\text { Rotación de } \\
\text { Empleo }\end{array}$ & $\begin{array}{c}\text { Participación } \\
\text { Vs } \\
\text { Posibilidades } \\
\text { de Crecimiento }\end{array}$ & 0.919 & $\begin{array}{c}\text { Positiva } \\
0<C P<1\end{array}$ & 0.845 \\
\hline
\end{tabular}

Fuente: Elaboración Propia (2017).

Al analizar el conjunto de variables, se determina la existencia de una correlación positiva en los tres casos. En la primera, al comparar los elementos de: posibilidades y oportunidades de crecimiento para las aristas de: rotación de empleo y desmotivación laboral, si los mileniales encuestados no perciben un ambiente laboral retador en el cual sean capaces de crecer, su desmotivación aumenta; por consiguiente, deciden abandonar la empresa para la cual laboran.

Por otra parte, el segundo coeficiente devela la correlación de variables más alta de las tres, por lo cual conforme un milenial carezca de oportunidades de crecimiento, su participación en la toma de decisiones irá en retroceso, lo cual provoca una escasa motivación; y de manera directa, tendrá un menor grado de compromiso con los objetivos y la cultura organizacional.

Finalmente, si bien la correlación realizada entre las incógnitas: carencia de compromiso y rotación laboral es positiva, el coeficiente es menor en comparación con los otros dos. Es decir, si bien existe afinidad entre ambas variables, la participación de un milenial en la toma de decisiones no es garantía de mayores posibilidades de crecimiento; por consiguiente, es concordante con la información develada previamente por los entrevistados, en la cual muchos integrantes de este grupo etario tienen todas las condiciones para ascender dentro la organización, pero le son limitadas sus oportunidades. 
Si bien los resultados de la pesquisa aplican para una organización específica, se ha logrado demostrar que existe una correlación positiva entre: la rotación de empleo, la desmotivación laboral y la carencia de compromiso de los mileniales costarricenses y el nivel de competitividad de las empresas tecnológicas. De acuerdo con la postura de los mileniales entrevistados, la empresa es poco competitiva en torno a: planes de carrera, oportunidades de crecimiento, participación de los mandos inferiores en la toma de decisiones, lo cual genera que el $54 \%$ de los encuestados se sientan desmotivados, el 33\% desee rotar hacia otra organización, y el 13\% no se sienta comprometido con la compañía. De persistir esta correlación positiva de variables, la organización puede perder competitividad y valor en el mercado tecnológico de Costa Rica.

\section{Conclusiones}

Luego de realizar la presente indagación, el investigador logra concluir lo siguiente:

1. Existe una cantidad limitada de información en cuanto a la relación directa entre los mileniales; y como ellos aportan valor competitivo a las empresas tecnológicas en Costa Rica. Para indagar más sobre esta temática, el investigador aplicó un cuestionario en la compañía Fiserv CR en torno a las variables: rotación de empleo, desmotivación y carencia de compromiso laboral, para medir el grado de afinidad e impacto de estas aristas en la competitividad de la empresa. Lo anterior permite a futuros indagadores realizar pesquisas futuras siguiendo la metodología propuesta.

2. De acuerdo con la opinión de los mileniales entrevistados en la compañía Fiserv CR, dicha organización tecnológica adolece de tres problemas, los cuales los entrevistados visualizan en otras organizaciones del sector tecnológico: 1) ausencia de preparación previa a la hora de ascender a una persona a un puesto de mando, 2) poca inclusión de los empleados en la formulación de objetivos y en la toma de decisiones, y 3) escasa participación de los gerentes a la hora de desarrollar planes de crecimiento.

3. La mayoría de los entrevistados apoya la idea acerca de cómo la desmotivación laboral, la carencia de compromiso y la rotación de empleo impactan la competitividad de la empresa tecnológica Fiserv CR. Esto demuestra la existencia de una situación de inconformidad en la relación laboral por parte los mileniales que laboran en Fiserv CR. 
4. La desmotivación laboral tiene una alta influencia en torno a la rotación de empleo de los mileniales que laboran en la empresa Fiserv CR. Esto obedece a la carencia de oportunidades de crecimiento y a la ausencia de un plan de carrera para el desarrollo profesional de este grupo etario. Al no tener posibilidades reales de crecimiento, existe el riesgo de un aumento en la rotación por parte de dicho grupo generacional en la compañía, lo cual impactaría las finanzas y la imagen como empleador de Fiserv CR.

5. La desmotivación laboral impacta directamente el compromiso laboral de los mileniales de Fiserv CR. Al existir pocas posibilidades de participación, e inequidades en las mismas, se genera un ambiente de tensión entre los mileniales y sus compañeros de trabajo, lo que desencadena roces y un entorno laboral negativo. Esto conlleva a los empleados de esta compañía a buscar nuevas oportunidades laborales en otras organizaciones tecnológicas en Costa Rica, lo cual impacta la imagen empresarial, pues los asociados no cumplen con los objetivos gerenciales, ni con la calidad del servicio al cliente.

6. Si bien los resultados de la pesquisa aplican para una organización específica, se logró demostrar que existe una correlación positiva entre: la rotación de empleo, la desmotivación laboral y la carencia de compromiso de los mileniales costarricenses y el nivel de competitividad de las empresas tecnológicas. Por consiguiente, los resultados obtenidos pueden ser emulados por otras organizaciones similares, para así invertir más en el desarrollo profesional de sus empleados, y permitirles trascender dentro de la misma, lo cual a su vez devenga en oportunidades de participación en las decisiones empresariales; y a mediano plazo, fomenta un cambio en la cultura organizacional. De esta manera, se fortalece la imagen empresarial y el sentimiento de pertenencia.

\section{Recomendaciones}

1. Se recomienda a los mandos medios y superiores de la empresa Fiserv CR emplear métodos de motivación como: el rol del educador, para fortalecer la relación con los mileniales. Esta técnica permite a los empleados incorporar nuevos conocimientos al ambiente laboral; y de esta manera, se mejora el liderazgo, al derrocar las perspectivas de los modelos mecánicos y rígidos. Al mismo tiempo, se sugiere utilizar ejemplos de 
situaciones de aprendizaje, para fortalecer las relaciones laborales. Para lograrlo, la gerencia debe desarrollar estrategias para fomentar cambios en el pensamiento y en las formas en las cuales se conciben: los objetivos, las estrategias, y la cultura empresarial.

2. Se propone a los líderes de las unidades de negocios de la empresa tecnológica Fiserv CR trabajar juntamente con el departamento de Recursos Humanos, para rediseñar los planes de transición de roles, y así generar un mayor compromiso por parte de los empleados; de lo contrario, el grupo etario milenial encuestado abandonará dicha organización, lo cual le restará competitividad a la misma. Una buena forma de lograrlo es mediante reuniones semanales en las cuales se revisen los puestos y se incorporen a los mileniales para entender cuáles áreas los desmotivan y cómo mejorarlas.

3. Se insta al departamento de Recursos Humanos de Fiserv CR a trabajar con los mileniales en torno a temas relacionados con la inequidad en el acceso a oportunidades y en las brechas salariales que existen entre los mismos puestos a nivel organizacional. Para ello, se pueden organizar reuniones mensuales con las gerencias y revisar continuamente: los paquetes de beneficios y el diseño de puestos, con el fin de reducir las inequidades existentes y así elevar el nivel competitivo de la empresa, no solo para retener al talento milenial actual, sino también para capturar a los mileniales que laboren en otras compañías o se encuentren desempleados.

\section{Referencias bibliográficas}

Alarcón, D. (2015). Estilo de vida de los mileniales. Recuperado de: http://www.eltiempo.com/estilo-de-vida/gente/generacion-millennial-jovenes-nacidosentre-1981-y-el-2000/15860315

Álvarez, E. (2014). La generación del milenio o Generación Y. Recuperado de: http://www.colombiadigital.net/actualidad/articulos-informativos/item/6210-lageneracion-del-milenio-o-generacion-y.html

Andert, D. (2011). Alternating leadership as a proactive organizational intervention: Addressing the needs of the Baby Boomers, Generation Xers and Millennials. Recuperado de: http://m.www.na-businesspress.com/JLAE/Andert84Web.pdf 
Bibliotecas. Vol. 37, № 1, enero - junio, 2019. EISSN: 1659-3286

URL: http://www.revistas.una.ac.cr/index.php/bibliotecas/index

Ángel, D. (2011). La hermenéutica y los métodos de investigación en ciencias sociales. Colombia: Universidad Autónoma de Manizales.

Babbie, E. (2000). Fundamentos de la investigación social. México, D.F.: International Thomson Editores.

Banco Central de Costa Rica. (2017). Plan macroeconómico 2017-2018. Recuperado de: http://www.bccr.fi.cr/publicaciones/politica monetaria inflacion/PM 2017-2018.pdf

Benvenuto, S. (2014). ¿Qué son los millennials? ¿Eres tú uno de ellos? Recuperado de: http://www.batanga.com/curiosidades/7936/que-son-los-millennials-eres-tu-uno-de-ellos Bisquerra, R. (2000). Métodos de investigación educativa. Barcelona: Grupo Editorial Ceac, S.A. Davis, K., y Newstrom, J. (2003). Comportamiento humano en el trabajo. (11a. ed.). Estados Unidos de América: McGraw Hill.

EcuRed. (2017). La investigación no experimental. Recuperado de: https://www.ecured.cu/Investigaci\%C3\%B3n no experimental

Emeagwali, S. (2011). Millennials: Leading the charge for change. Recuperado de: https://eric.ed.gov/?id=EJ925286

Fernández,

A.

(2012).

Sociedad milenial.

Recuperado

de:

https://www.abc.es/20121103/sociedad/abci-millennials-generacion-201211021603.html

Gibson, L. y Sodeman, W. (2014). Millennials and technology: Addressing the communication gap in education and practice. Recuperado de: https://hpu.edu/CBA/block-leftcolumn/gibsonPublication.pdf

Hernández, R. Fernández, C., y Baptista, P. (2010). Metodología de la investigación (5a.ed.). México: McGraw Hill.

Hewitt, M. y Ukpere, W. (2012). Leadership challenges associated with the management of Generation $Y$ employees: A proposed theoretical model. Recuperado de: http://search.proquest.com/openview/4b6aa3631b349986107e43fc70cabc93/1 ?pqorigsite $=$ gscholar $\& \mathrm{cbl}=816394$

Hroncich, C. (2017). Does the changing workforce impact IT? Recuperado de: http://www.pharmtech.com/does-changing-workforce-demographic-impact-iiot

Levy, Y., y Ellis, T. J. (2006). A systems approach to conduct an effective literature review in support of information systems research. Informing Science: International Journal of an Emerging Trans discipline, 9 (1), 181-212. 
Bibliotecas. Vol. 37, № 1, enero - junio, 2019. EISSN: 1659-3286

URL: http://www.revistas.una.ac.cr/index.php/bibliotecas/index

Meister, J. y Willyerd, K. (2010). Mentoring millennials. Recuperado de: http://managingmultigenerationalworkforce.pbworks.com/f/Millenium.pdf

Méndez, R. (2014 a). Teoría del liderazgo: Material para el curso de Administración de Proyectos II capítulo: Habilidades del gerente de proyectos. Cartago, C.R.: Instituto Tecnológico de Costa Rica.

Méndez, R. (2014 b). Teorías del aprendizaje y de la inteligencia: Material para el curso de Administración de Proyectos // Cap: Habilidades del gerente de proyectos. Cartago, C.R.: Instituto Tecnológico de Costa Rica.

Morgan, G. (1986). Images of Organization. Estados Unidos de América: Sage Publications Inc.

Nava, M. (2014). La paradoja de la generación del milenio. Recuperado de: https://www.bbvaresearch.com/publicaciones/la-paradoja-de-la-generacion-del-milenio/

Organización de Técnicas de Estudio. (2017). El método transeccional. Recuperado de: http://www.tecnicas-de-estudio.org/investigacion/investigacion39.htm

Ortega, C. (2015). Mileniales empleados o emprendedores. Recuperado de: http://www.youngmarketing.co/millennials-empleados-o-emprendedores/

Ramos, E. (2008). Métodos y técnicas de investigación. Recuperado de: https://www.gestiopolis.com/metodos-y-tecnicas-de-investigacion/

Retamal, G. (2007). Desarrollo de estrategias. Recuperado de: www.leonismoargentino.com

Sanz, S. (2015). Comparando a los mileniales con sus predecesores. Recuperado de: https://books.google.es/books?hl=es\&lr=\&id=hzWeDAAAQBAJ\&oi=fnd\&pg=PA9\&dq=S anz $+2015+$ millennials\&ots $=7 \mathrm{QHXe4Fy50 \& sig=IQ-}$

ESJUsOscT8Pmrr9dmH 1Pnoo\#v=onepage\&q=Sanz\%202015\%20millennials\&f=false

Softline. (2016). Gerenciando equipos mileniales. Recuperado de: http://costarica.softlinegroup.com/como-gerenciar-equipos-de-millennials/

Suárez, M. (2014). El coeficiente de correlación de Pearson. Recuperado de: http://www.monografias.com/trabajos85/coeficiente-correlacion-karlpearson/coeficiente-correlacion-karl-pearson.shtml 


\section{Notas del autor}

Fernando Gutiérrez Benavides, máster en Finanzas y Comercio Internacional, con más de 9 años de experiencia como analista de negocios; y en los últimos 8 años, se ha distinguido en empresas multinacionales de los sectores de Finanzas y Tecnología, en roles de: análisis, coordinación, liderazgo, y ejecución de proyectos financieros. Desde el 2012, labora en la empresa Fiserv CR, y actualmente es el líder del Equipo de Soporte para el producto Aperio, para instituciones financieras en EE.UU. Previamente, trabajó en entidades financieras como Banco HSBC y Banco de América durante el período 2010-2012. Correo: fmrbenavides@gmail.com. 


\section{Anexos}

Anexo 1: Cuestionario sobre las perspectivas de los mileniales costarricenses acerca del impacto de las variables: rotación de empleo, desmotivación y carencia de compromiso laboral en las compañías tecnológicas que radican en Costa Rica.

Se seleccionaron 65 mileniales costarricenses que laboran en la empresa Fiserv CR para conocer sus opiniones sobre cómo la rotación de empleo, la desmotivación laboral y la carencia de compromiso impactan a las empresas de tecnología ubicadas en Costa Rica. El cuestionario fue aplicado en horas laborales (de 8am a 5pm) los días lunes a viernes, en la semana del 19 al 23 de junio del 2017. La información suministrada es exclusivamente para efectos académicos y no comerciales. Favor marcar solo una opción para cada pregunta. De antemano se le agradece su colaboración.

1. ¿Cuánto tiempo lleva laborando para la empresa Fiserv CR?

a) 1-3 años ( )

b) 3-5 años ( )

c) 5 años o más ( )

2. Evalúe del 1 al 5 , siendo el 5 el más importante y 1 el menos importante, cuál de los siguientes aspectos genera la mayor rotación de empleo en las empresas de tecnología en Costa Rica:

\begin{tabular}{|l|l|l|l|l|l|}
\hline \multicolumn{1}{|c|}{ Elemento } & $\mathbf{1}$ & $\mathbf{2}$ & $\mathbf{3}$ & $\mathbf{4}$ & $\mathbf{5}$ \\
\hline Carencia de beneficios & & & & & \\
\hline $\begin{array}{l}\text { Horarios de trabajo/ } \\
\text { Tele trabajo }\end{array}$ & & & & & \\
\hline Lejanía del trabajo de & & & & & \\
\hline $\begin{array}{l}\text { Posibilidades } \\
\text { crecimiento }\end{array}$ & & & & \\
\hline Salario & & & & \\
\hline
\end{tabular}


3. Evalúe del 1 al 5 , siendo el 5 el más importante y 1 el menos importante, cuál de los siguientes aspectos genera la mayor desmotivación laboral en las empresas de tecnología en Costa Rica:

\begin{tabular}{|l|l|l|l|l|l|}
\hline \multicolumn{1}{|c|}{ Elemento } & $\mathbf{1}$ & $\mathbf{2}$ & $\mathbf{3}$ & $\mathbf{4}$ & $\mathbf{5}$ \\
\hline $\begin{array}{l}\text { Ambiente } \\
\text { laboral }\end{array}$ & & & & & \\
\hline $\begin{array}{l}\text { Cultura } \\
\text { organizacional }\end{array}$ & & & & & \\
\hline $\begin{array}{l}\text { Objetivos poco } \\
\text { claros }\end{array}$ & & & & & \\
\hline $\begin{array}{l}\text { Oportunidades } \\
\text { de crecimiento }\end{array}$ & & & & & \\
\hline $\begin{array}{l}\text { Plan de } \\
\text { carrera } \\
\text { profesional }\end{array}$ & & & & & \\
\hline
\end{tabular}

4. Evalúe del 1 al 5 , siendo el 5 el más importante y 1 el menos importante, cuál de los siguientes aspectos genera la mayor carencia de compromiso laboral en las empresas de tecnología en Costa Rica:

\begin{tabular}{|l|l|l|l|l|l|}
\hline \multicolumn{1}{|c|}{ Elemento } & $\mathbf{1}$ & $\mathbf{2}$ & $\mathbf{3}$ & $\mathbf{4}$ & $\mathbf{5}$ \\
\hline $\begin{array}{l}\text { Claridad de } \\
\text { objetivos }\end{array}$ & & & & & \\
\hline Entrenamientos & & & & & \\
\hline Liderazgo & & & & & \\
\hline $\begin{array}{l}\text { Participación } \\
\text { en la toma de } \\
\text { decisiones }\end{array}$ & & & & & \\
\hline Plan de Carrera & & & & & \\
\hline
\end{tabular}

5. ¿Considera usted que la rotación de empleo, la desmotivación laboral y la carencia de compromiso laboral mejoran la competitividad laboral de las empresas tecnológicas ubicadas en Costa Rica?
a) Sí ( )
b) No ( )

6. De los siguientes aspectos, cuál considera usted tiene el mayor nivel de impacto en la competitividad laboral de las empresas tecnológicas ubicadas en Costa Rica: 

a) Carencia de Compromiso laboral ( )
b) Desmotivación Laboral ( )
c) Rotación de Empleo ( )

7. Evalúe del 1 al 5 , siendo el 5 el más importante y 1 el menos importante, cuál de los siguientes aspectos mejoraría la competitividad empresarial de las empresas tecnológicas ubicadas en Costa Rica:

\begin{tabular}{|l|l|l|l|l|l|}
\hline \multicolumn{1}{|c|}{ Elemento } & $\mathbf{1}$ & $\mathbf{2}$ & $\mathbf{3}$ & $\mathbf{4}$ & $\mathbf{5}$ \\
\hline $\begin{array}{l}\text { Ambiente } \\
\text { Laboral }\end{array}$ & & & & & \\
\hline $\begin{array}{l}\text { Condiciones } \\
\text { laborales }\end{array}$ & & & & & \\
\hline $\begin{array}{l}\text { Estilo de } \\
\text { liderazgo }\end{array}$ & & & & & \\
\hline $\begin{array}{l}\text { Inversión en } \\
\text { el desarrollo } \\
\text { profesional } \\
\text { de los }\end{array}$ & & & & & \\
empleados & & & & & \\
\hline $\begin{array}{l}\text { Participación } \\
\text { de los }\end{array}$ & & & & & \\
empleados \\
en la toma de \\
decisiones.
\end{tabular}


Bibliotecas. Vol. 37, № 1, enero - junio, 2019. EISSN: 1659-3286

URL: http://www.revistas.una.ac.cr/index.php/bibliotecas/index

Anexo 2- Correlación de las variables

Rotación de Empleo vs Desmotivación Laboral

\begin{tabular}{|c|c|c|c|c|c|c|c|}
\hline Sujeto & $\mathbf{X}$ & $\mathbf{Y}$ & $\begin{array}{c}\mathbf{x}- \\
\text { xprom }\end{array}$ & $\begin{array}{c}\mathbf{y}- \\
\text { yprom }\end{array}$ & $\begin{array}{c}(\mathbf{x}- \\
\text { xprom }^{2}\end{array}$ & $\begin{array}{c}(\mathbf{y}- \\
\text { yprom }^{2}\end{array}$ & $\begin{array}{c}\text { (x-xprom)(y- } \\
\text { yprom) }\end{array}$ \\
\hline 1 & 5 & 5 & 1 & 2 & 1 & 2 & 2 \\
\hline 2 & 5 & 5 & 1 & 2 & 1 & 2 & 2 \\
\hline 3 & 5 & 5 & 1 & 2 & 1 & 2 & 2 \\
\hline 4 & 5 & 5 & 1 & 2 & 1 & 2 & 2 \\
\hline 5 & 5 & 5 & 1 & 2 & 1 & 2 & 2 \\
\hline 6 & 5 & 5 & 1 & 2 & 1 & 2 & 2 \\
\hline 7 & 5 & 5 & 1 & 2 & 1 & 2 & 2 \\
\hline 8 & 5 & 5 & 1 & 2 & 1 & 2 & 2 \\
\hline 9 & 5 & 5 & 1 & 2 & 1 & 2 & 2 \\
\hline 10 & 5 & 5 & 1 & 2 & 1 & 2 & 2 \\
\hline 11 & 5 & 5 & 1 & 2 & 1 & 2 & 2 \\
\hline 12 & 5 & 5 & 1 & 2 & 1 & 2 & 2 \\
\hline 13 & 5 & 5 & 1 & 2 & 1 & 2 & 2 \\
\hline 14 & 5 & 5 & 1 & 2 & 1 & 2 & 2 \\
\hline 15 & 5 & 5 & 1 & 2 & 1 & 2 & 2 \\
\hline 16 & 5 & 5 & 1 & 2 & 1 & 2 & 2 \\
\hline 17 & 5 & 5 & 1 & 2 & 1 & 2 & 2 \\
\hline
\end{tabular}
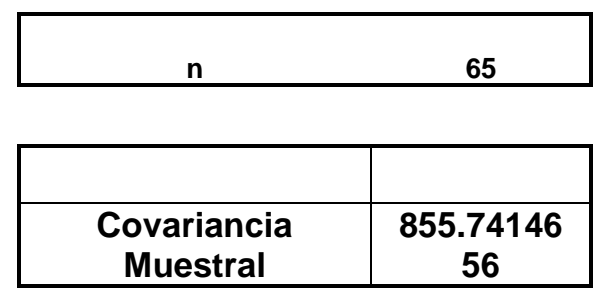

\begin{tabular}{|c|c|}
\hline Varx & 969.84 \\
\hline Sigmax & 31.14 \\
\hline
\end{tabular}

\begin{tabular}{|c|c|}
\hline Vary & 755.07 \\
\hline Sigmay & 27.48 \\
\hline
\end{tabular}

\begin{tabular}{|l|l|}
\hline Coef Pearson & $\mathbf{1 . 0 0 0}$ \\
\hline
\end{tabular}

\begin{tabular}{|l|l|}
\hline r Cuadrado & $87 \%$ \\
\hline
\end{tabular}

\begin{tabular}{|l|l|l|l|l|l|l|l|}
\hline 18 & 5 & 5 & 1 & 2 & 1 & 2 & 2 \\
\hline 19 & 5 & 5 & 1 & 2 & 1 & 2 & 2 \\
\hline 20 & 5 & 5 & 1 & 2 & 1 & 2 & 2 \\
\hline 21 & 5 & 4 & 1 & 1 & 1 & 0 & 1 \\
\hline 22 & 5 & 4 & 1 & 1 & 1 & 0 & 1 \\
\hline 23 & 5 & 4 & 1 & 1 & 1 & 0 & 1 \\
\hline 24 & 5 & 4 & 1 & 1 & 1 & 0 & 1 \\
\hline 25 & 5 & 4 & 1 & 1 & 1 & 0 & 1 \\
\hline 26 & 5 & 4 & 1 & 1 & 1 & 0 & 1 \\
\hline 27 & 5 & 4 & 1 & 1 & 1 & 0 & 1 \\
\hline 28 & 5 & 4 & 1 & 1 & 1 & 0 & 1 \\
\hline 29 & 5 & 4 & 1 & 1 & 1 & 0 & 1 \\
\hline 30 & 5 & 4 & 1 & 1 & 1 & 0 & 1 \\
\hline 31 & 4 & 4 & 0 & 1 & 0 & 0 & 0 \\
\hline
\end{tabular}


Bibliotecas. Vol. 37, № 1, enero - junio, 2019. EISSN: 1659-3286 URL: http://www.revistas.una.ac.cr/index.php/bibliotecas/index

\begin{tabular}{|c|c|c|c|c|c|c|c|}
\hline 32 & 4 & 4 & 0 & 1 & 0 & 0 & 0 \\
\hline 33 & 4 & 4 & 0 & 1 & 0 & 0 & 0 \\
\hline 34 & 4 & 4 & 0 & 1 & 0 & 0 & 0 \\
\hline 35 & 4 & 4 & 0 & 1 & 0 & 0 & 0 \\
\hline 36 & 4 & 3 & 0 & 0 & 0 & 0 & 0 \\
\hline 37 & 4 & 3 & 0 & 0 & 0 & 0 & 0 \\
\hline 38 & 4 & 3 & 0 & 0 & 0 & 0 & 0 \\
\hline 39 & 4 & 3 & 0 & 0 & 0 & 0 & 0 \\
\hline 40 & 4 & 3 & 0 & 0 & 0 & 0 & 0 \\
\hline 41 & 4 & 3 & 0 & 0 & 0 & 0 & 0 \\
\hline 42 & 4 & 3 & 0 & 0 & 0 & 0 & 0 \\
\hline 43 & 4 & 3 & 0 & 0 & 0 & 0 & 0 \\
\hline 44 & 4 & 3 & 0 & 0 & 0 & 0 & 0 \\
\hline 45 & 4 & 3 & 0 & 0 & 0 & 0 & 0 \\
\hline 46 & 3 & 3 & -1 & 0 & 1 & 0 & 0 \\
\hline 47 & 3 & 3 & -1 & 0 & 1 & 0 & 0 \\
\hline 48 & 3 & 3 & -1 & 0 & 1 & 0 & 0 \\
\hline 49 & 3 & 3 & -1 & 0 & 1 & 0 & 0 \\
\hline 50 & 3 & 3 & -1 & 0 & 1 & 0 & 0 \\
\hline 51 & 3 & 2 & -1 & -1 & 1 & 2 & 1 \\
\hline 52 & 3 & 2 & -1 & -1 & 1 & 2 & 1 \\
\hline 53 & 3 & 2 & -1 & -1 & 1 & 2 & 1 \\
\hline 54 & 3 & 2 & -1 & -1 & 1 & 2 & 1 \\
\hline 55 & 3 & 2 & -1 & -1 & 1 & 2 & 1 \\
\hline 56 & 2 & 1 & -2 & -2 & 4 & 6 & 5 \\
\hline 57 & 2 & 1 & -2 & -2 & 4 & 6 & 5 \\
\hline 58 & 2 & 1 & -2 & -2 & 4 & 6 & 5 \\
\hline 59 & 2 & 1 & -2 & -2 & 4 & 6 & 5 \\
\hline 60 & 2 & 1 & -2 & -2 & 4 & 6 & 5 \\
\hline 61 & 1 & 1 & -3 & -2 & 9 & 6 & 7 \\
\hline 62 & 1 & 1 & -3 & -2 & 9 & 6 & 7 \\
\hline 63 & 1 & 1 & -3 & -2 & 9 & 6 & 7 \\
\hline 64 & 1 & 1 & -3 & -2 & 9 & 6 & 7 \\
\hline 65 & 1 & 1 & -3 & -2 & 9 & 6 & 7 \\
\hline Total & 255 & 225 & 251 & 222 & 63040 & 49079 & 55623 \\
\hline Promedio & 4 & 3 & & & & & \\
\hline
\end{tabular}


Bibliotecas. Vol. 37, № 1, enero - junio, 2019. EISSN: 1659-3286 URL: http://www.revistas.una.ac.cr/index.php/bibliotecas/index

\section{Desmotivación Laboral vs Carencia de Compromiso}

\begin{tabular}{|c|c|c|c|c|c|c|c|}
\hline Sujeto & $\mathbf{X}$ & $\mathbf{Y}$ & $\begin{array}{c}\mathbf{X}- \\
\text { xpro } \\
\mathbf{m}\end{array}$ & $\begin{array}{c}\mathbf{y}- \\
\text { ypro } \\
\mathbf{m}\end{array}$ & $\begin{array}{c}\mathbf{( x -} \\
\mathbf{x p r o m} \\
\mathbf{2}^{\mathbf{2}}\end{array}$ & $\begin{array}{c}\text { (y- } \\
\text { yprom } \\
\mathbf{~}^{\mathbf{2}}\end{array}$ & $\begin{array}{c}\text { (x-xprom)(y- } \\
\text { yprom) }\end{array}$ \\
\hline 1 & 5 & 5 & 2 & 2 & 2 & 3 & 3 \\
\hline 2 & 5 & 5 & 2 & 2 & 2 & 3 & 3 \\
\hline 3 & 5 & 5 & 2 & 2 & 2 & 3 & 3 \\
\hline 4 & 5 & 5 & 2 & 2 & 2 & 3 & 3 \\
\hline 5 & 5 & 5 & 2 & 2 & 2 & 3 & 3 \\
\hline 6 & 5 & 5 & 2 & 2 & 2 & 3 & 3 \\
\hline 7 & 5 & 5 & 2 & 2 & 2 & 3 & 3 \\
\hline 8 & 5 & 5 & 2 & 2 & 2 & 3 & 3 \\
\hline 9 & 5 & 5 & 2 & 2 & 2 & 3 & 3 \\
\hline 10 & 5 & 5 & 2 & 2 & 2 & 3 & 3 \\
\hline 11 & 5 & 5 & 2 & 2 & 2 & 3 & 3 \\
\hline 12 & 5 & 5 & 2 & 2 & 2 & 3 & 3 \\
\hline 13 & 5 & 5 & 2 & 2 & 2 & 3 & 3 \\
\hline 14 & 5 & 5 & 2 & 2 & 2 & 3 & 3 \\
\hline 15 & 5 & 5 & 2 & 2 & 2 & 3 & 3 \\
\hline 16 & 5 & 5 & 2 & 2 & 2 & 3 & 3 \\
\hline 17 & 5 & 5 & 2 & 2 & 2 & 3 & 3 \\
\hline 18 & 5 & 5 & 2 & 2 & 2 & 3 & 3 \\
\hline 19 & 5 & 5 & 2 & 2 & 2 & 3 & 3 \\
\hline 20 & 5 & 5 & 2 & 2 & 2 & 3 & 3 \\
\hline 21 & 4 & 4 & 1 & 1 & 0 & 0 & 0 \\
\hline 22 & 4 & 4 & 1 & 1 & 0 & 0 & 0 \\
\hline 23 & 4 & 4 & 1 & 1 & 0 & 0 & 0 \\
\hline 24 & 4 & 4 & 1 & 1 & 0 & 0 & 0 \\
\hline 25 & 4 & 4 & 1 & 1 & 0 & 0 & 0 \\
\hline 26 & 4 & 4 & 1 & 1 & 0 & 0 & 0 \\
\hline 27 & 4 & 4 & 1 & 1 & 0 & 0 & 0 \\
\hline 28 & 4 & 4 & 1 & 1 & 0 & 0 & 0 \\
\hline 29 & 4 & 4 & 1 & 1 & 0 & 0 & 0 \\
\hline 30 & 4 & 4 & 1 & 1 & 0 & 0 & 0 \\
\hline 31 & 4 & 4 & 1 & 1 & 0 & 0 & 0 \\
\hline 32 & 4 & 4 & 1 & 1 & 0 & 0 & 0 \\
\hline 33 & 4 & 4 & 1 & 1 & 0 & 0 & 0 \\
\hline 34 & 4 & 4 & 1 & 1 & 0 & 0 & 0 \\
\hline & & & & & & \\
\hline
\end{tabular}

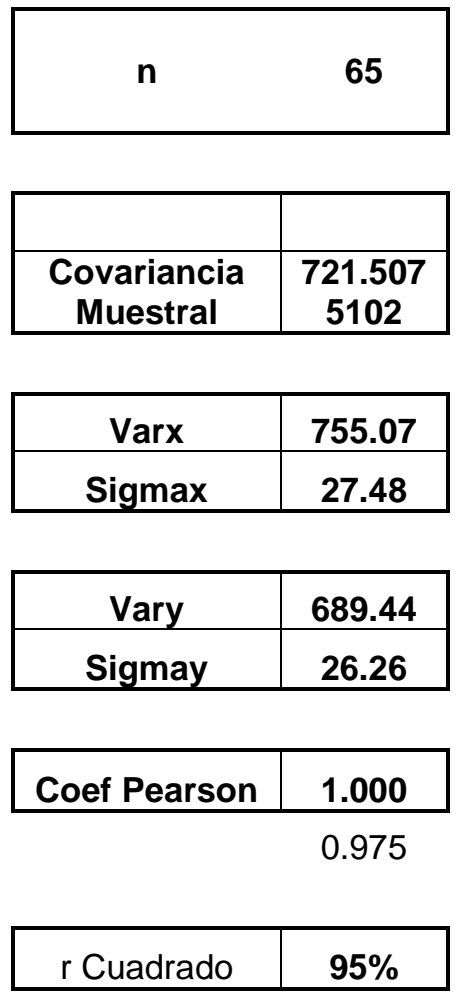


Bibliotecas. Vol. 37, № 1, enero - junio, 2019. EISSN: 1659-3286

URL: http://www.revistas.una.ac.cr/index.php/bibliotecas/index

\begin{tabular}{|c|c|c|c|c|c|c|c|}
\hline 35 & 4 & 4 & 1 & 1 & 0 & 0 & 0 \\
\hline 36 & 3 & 3 & 0 & 0 & 0 & 0 & 0 \\
\hline 37 & 3 & 3 & 0 & 0 & 0 & 0 & 0 \\
\hline 38 & 3 & 3 & 0 & 0 & 0 & 0 & 0 \\
\hline 39 & 3 & 3 & 0 & 0 & 0 & 0 & 0 \\
\hline 40 & 3 & 3 & 0 & 0 & 0 & 0 & 0 \\
\hline 41 & 3 & 3 & 0 & 0 & 0 & 0 & 0 \\
\hline 42 & 3 & 3 & 0 & 0 & 0 & 0 & 0 \\
\hline 43 & 3 & 3 & 0 & 0 & 0 & 0 & 0 \\
\hline 44 & 3 & 3 & 0 & 0 & 0 & 0 & 0 \\
\hline 45 & 3 & 3 & 0 & 0 & 0 & 0 & 0 \\
\hline 46 & 3 & 2 & 0 & -1 & 0 & 2 & 1 \\
\hline 47 & 3 & 2 & 0 & -1 & 0 & 2 & 1 \\
\hline 48 & 3 & 2 & 0 & -1 & 0 & 2 & 1 \\
\hline 49 & 3 & 2 & 0 & -1 & 0 & 2 & 1 \\
\hline 50 & 3 & 2 & 0 & -1 & 0 & 2 & 1 \\
\hline 51 & 2 & 1 & -1 & -2 & 2 & 5 & 3 \\
\hline 52 & 2 & 1 & -1 & -2 & 2 & 5 & 3 \\
\hline 53 & 2 & 1 & -1 & -2 & 2 & 5 & 3 \\
\hline 54 & 2 & 1 & -1 & -2 & 2 & 5 & 3 \\
\hline 55 & 2 & 1 & -1 & -2 & 2 & 5 & 3 \\
\hline 56 & 1 & 1 & -2 & -2 & 6 & 5 & 6 \\
\hline 57 & 1 & 1 & -2 & -2 & 6 & 5 & 6 \\
\hline 58 & 1 & 1 & -2 & -2 & 6 & 5 & 6 \\
\hline 59 & 1 & 1 & -2 & -2 & 6 & 5 & 6 \\
\hline 60 & 1 & 1 & -2 & -2 & 6 & 5 & 6 \\
\hline 61 & 1 & 1 & -2 & -2 & 6 & 5 & 6 \\
\hline 62 & 1 & 1 & -2 & -2 & 6 & 5 & 6 \\
\hline 63 & 1 & 1 & -2 & -2 & 6 & 5 & 6 \\
\hline 64 & 1 & 1 & -2 & -2 & 6 & 5 & 6 \\
\hline 65 & 1 & 1 & -2 & -2 & 6 & 5 & 6 \\
\hline Total & $\begin{array}{l}2 \\
2 \\
5\end{array}$ & $\begin{array}{l}2 \\
1 \\
5\end{array}$ & 222 & 212 & 49079 & 44814 & 46898 \\
\hline $\begin{array}{c}\text { Prome- } \\
\text { dio }\end{array}$ & 3 & 3 & & & & & \\
\hline
\end{tabular}


Bibliotecas. Vol. 37, № 1, enero - junio, 2019. EISSN: 1659-3286

URL: http://www.revistas.una.ac.cr/index.php/bibliotecas/index

Carencia de Compromiso vs Rotación de Empleo

\begin{tabular}{|c|c|c|c|c|c|c|c|}
\hline Sujeto & $\mathbf{x}$ & $\mathbf{Y}$ & $\begin{array}{c}\text { X- } \\
\text { xpro } \\
m \\
\end{array}$ & $\begin{array}{c}\text { y- } \\
\text { ypro } \\
\mathbf{m} \\
\end{array}$ & $\begin{array}{c}\text { (x- } \\
\text { xprom) } \\
2\end{array}$ & $\begin{array}{c}\text { (y- } \\
\text { yprom) } \\
2\end{array}$ & $\begin{array}{c}\text { (x-xprom)(y- } \\
\text { yprom) }\end{array}$ \\
\hline 1 & 5 & 5 & 2 & 1 & 3 & 1 & 2 \\
\hline 2 & 5 & 5 & 2 & 1 & 3 & 1 & 2 \\
\hline 3 & 5 & 5 & 2 & 1 & 3 & 1 & 2 \\
\hline 4 & 5 & 5 & 2 & 1 & 3 & 1 & 2 \\
\hline 5 & 5 & 5 & 2 & 1 & 3 & 1 & 2 \\
\hline 6 & 5 & 5 & 2 & 1 & 3 & 1 & 2 \\
\hline 7 & 5 & 5 & 2 & 1 & 3 & 1 & 2 \\
\hline 8 & 5 & 5 & 2 & 1 & 3 & 1 & 2 \\
\hline 9 & 5 & 5 & 2 & 1 & 3 & 1 & 2 \\
\hline 10 & 5 & 5 & 2 & 1 & 3 & 1 & 2 \\
\hline 11 & 5 & 5 & 2 & 1 & 3 & 1 & 2 \\
\hline 12 & 5 & 5 & 2 & 1 & 3 & 1 & 2 \\
\hline 13 & 5 & 5 & 2 & 1 & 3 & 1 & 2 \\
\hline 14 & 5 & 5 & 2 & 1 & 3 & 1 & 2 \\
\hline 15 & 5 & 5 & 2 & 1 & 3 & 1 & 2 \\
\hline 16 & 5 & 5 & 2 & 1 & 3 & 1 & 2 \\
\hline 17 & 5 & 5 & 2 & 1 & 3 & 1 & 2 \\
\hline 18 & 5 & 5 & 2 & 1 & 3 & 1 & 2 \\
\hline 19 & 5 & 5 & 2 & 1 & 3 & 1 & 2 \\
\hline 20 & 5 & 5 & 2 & 1 & 3 & 1 & 2 \\
\hline 21 & 4 & 5 & 1 & 1 & 0 & 1 & 1 \\
\hline 22 & 4 & 5 & 1 & 1 & 0 & 1 & 1 \\
\hline 23 & 4 & 5 & 1 & 1 & 0 & 1 & 1 \\
\hline 24 & 4 & 5 & 1 & 1 & 0 & 1 & 1 \\
\hline 25 & 4 & 5 & 1 & 1 & 0 & 1 & 1 \\
\hline 26 & 4 & 5 & 1 & 1 & 0 & 1 & 1 \\
\hline 27 & 4 & 5 & 1 & 1 & 0 & 1 & 1 \\
\hline 28 & 4 & 5 & 1 & 1 & 0 & 1 & 1 \\
\hline 29 & 4 & 5 & 1 & 1 & 0 & 1 & 1 \\
\hline 30 & 4 & 5 & 1 & 1 & 0 & 1 & 1 \\
\hline 31 & 4 & 4 & 1 & 0 & 0 & 0 & 0 \\
\hline 32 & 4 & 4 & 1 & 0 & 0 & 0 & 0 \\
\hline 33 & 4 & 4 & 1 & 0 & 0 & 0 & 0 \\
\hline 34 & 4 & 4 & 1 & 0 & 0 & 0 & 0 \\
\hline
\end{tabular}

\begin{tabular}{|c|c|}
\hline $\mathbf{n}$ & 65 \\
\hline & \\
\hline $\begin{array}{c}\text { Covariancia } \\
\text { Muestral }\end{array}$ & $\begin{array}{c}817.708 \\
5116 \\
\end{array}$ \\
\hline Varx & 689.44 \\
\hline Sigmax & 26.26 \\
\hline Vary & 969.84 \\
\hline Sigmay & 31.14 \\
\hline Coef Pearson & 1.000 \\
\hline & 0.919 \\
\hline r Cuadrado & $84 \%$ \\
\hline
\end{tabular}


Bibliotecas. Vol. 37, № 1, enero - junio, 2019. EISSN: 1659-3286

URL: http://www.revistas.una.ac.cr/index.php/bibliotecas/index

\begin{tabular}{|c|c|c|c|c|c|c|c|}
\hline 35 & 4 & 4 & 1 & 0 & 0 & 0 & 0 \\
\hline 36 & 3 & 4 & 0 & 0 & 0 & 0 & 0 \\
\hline 37 & 3 & 4 & 0 & 0 & 0 & 0 & 0 \\
\hline 38 & 3 & 4 & 0 & 0 & 0 & 0 & 0 \\
\hline 39 & 3 & 4 & 0 & 0 & 0 & 0 & 0 \\
\hline 40 & 3 & 4 & 0 & 0 & 0 & 0 & 0 \\
\hline 41 & 3 & 4 & 0 & 0 & 0 & 0 & 0 \\
\hline 42 & 3 & 4 & 0 & 0 & 0 & 0 & 0 \\
\hline 43 & 3 & 4 & 0 & 0 & 0 & 0 & 0 \\
\hline 44 & 3 & 4 & 0 & 0 & 0 & 0 & 0 \\
\hline 45 & 3 & 4 & 0 & 0 & 0 & 0 & 0 \\
\hline 46 & 2 & 3 & -1 & -1 & 2 & 1 & 1 \\
\hline 47 & 2 & 3 & -1 & -1 & 2 & 1 & 1 \\
\hline 48 & 2 & 3 & -1 & -1 & 2 & 1 & 1 \\
\hline 49 & 2 & 3 & -1 & -1 & 2 & 1 & 1 \\
\hline 50 & 2 & 3 & -1 & -1 & 2 & 1 & 1 \\
\hline 51 & 1 & 3 & -2 & -1 & 5 & 1 & 2 \\
\hline 52 & 1 & 3 & -2 & -1 & 5 & 1 & 2 \\
\hline 53 & 1 & 3 & -2 & -1 & 5 & 1 & 2 \\
\hline 54 & 1 & 3 & -2 & -1 & 5 & 1 & 2 \\
\hline 55 & 1 & 3 & -2 & -1 & 5 & 1 & 2 \\
\hline 56 & 1 & 2 & -2 & -2 & 5 & 4 & 4 \\
\hline 57 & 1 & 2 & -2 & -2 & 5 & 4 & 4 \\
\hline 58 & 1 & 2 & -2 & -2 & 5 & 4 & 4 \\
\hline 59 & 1 & 2 & -2 & -2 & 5 & 4 & 4 \\
\hline 60 & 1 & 2 & -2 & -2 & 5 & 4 & 4 \\
\hline 61 & 1 & 1 & -2 & -3 & 5 & 9 & 7 \\
\hline 62 & 1 & 1 & -2 & -3 & 5 & 9 & 7 \\
\hline 63 & 1 & 1 & -2 & -3 & 5 & 9 & 7 \\
\hline 64 & 1 & 1 & -2 & -3 & 5 & 9 & 7 \\
\hline 65 & 1 & 1 & -2 & -3 & 5 & 9 & 7 \\
\hline Total & $\begin{array}{l}2 \\
1 \\
5\end{array}$ & $\begin{array}{c}25 \\
5\end{array}$ & 212 & 251 & 44814 & 63040 & 53151 \\
\hline $\begin{array}{c}\begin{array}{c}\text { Prome- } \\
\text { dio }\end{array} \\
\end{array}$ & 3 & 4 & & & & & \\
\hline
\end{tabular}

